\title{
Iron (III)-Quercetin Complex: Synthesis, Physicochemical Characterization, and MRI Cell Tracking toward Potential Applications in Regenerative Medicine
}

\author{
Phakorn Papan, ${ }^{1,2}$ Jiraporn Kantapan $\mathbb{D}^{1},{ }^{1}$ Padchanee Sangthong $\mathbb{D},{ }^{2}$ \\ Puttinan Meepowpan $\mathbb{D}^{2},{ }^{2}$ and Nathupakorn Dechsupa $\mathbb{D}^{1}$ \\ ${ }^{1}$ Research Unit of Molecular Imaging Probes and Radiobiology, Department of Radiologic Technology, \\ Faculty of Associated Medical Sciences, Chiang Mai University, Chiang Mai 50200, Thailand \\ ${ }^{2}$ Department of Chemistry, Faculty of Science, Chiang Mai University, Chiang Mai 50200, Thailand
}

Correspondence should be addressed to Nathupakorn Dechsupa; nathupakorn.d@cmu.ac.th

Received 15 August 2020; Revised 9 December 2020; Accepted 16 December 2020; Published 29 December 2020

Academic Editor: Michael J. Evans

Copyright (c) 2020 Phakorn Papan et al. This is an open access article distributed under the Creative Commons Attribution License, which permits unrestricted use, distribution, and reproduction in any medium, provided the original work is properly cited.

\begin{abstract}
In cell therapy, contrast agents $\mathrm{T} 1$ and $\mathrm{T} 2$ are both needed for the labeling and tracking of transplanted stem cells over extended periods of time through magnetic resonance imaging (MRI). Importantly, the metal-quercetin complex via coordination chemistry has been studied extensively for biomedical applications, such as anticancer therapies and imaging probes. Herein, we report on the synthesis, characterization, and labeling of the iron (III)-quercetin complex, "IronQ," in circulating proangiogenic cells (CACs) and also explore tracking via the use of a clinical 1.5 Tesla (T) MRI scanner. Moreover, IronQ had a paramagnetic T1 positive contrast agent property with a saturation magnetization of $0.155 \mathrm{emu} / \mathrm{g}$ at $1.0 \mathrm{~T}$ and longitudinal relaxivity $(\mathrm{r} 1)$ values of 2.29 and $3.70 \mathrm{mM}^{-1} \mathrm{~s}^{-1}$ at $1.5 \mathrm{~T}$ for water and human plasma, respectively. Surprisingly, IronQ was able to promote CAC growth in conventional cell culture systems without the addition of specific growth factors. Increasing dosages of IronQ from 0 to $200 \mu \mathrm{g} / \mathrm{mL}$ led to higher CAC uptake, and maximum labeling time was achieved in 10 days. The accumulated IronQ in CACs was measured by two methodologies, an inductively coupled plasma optical emission spectrometry (ICP-EOS) and T1-weighted MRI. In our research, we confirmed that IronQ has excellent dual functions with the use of an imaging probe for MRI. IronQ can also act as a stimulating agent by favoring circulating proangiogenic cell differentiation. Optimistically, IronQ is considered beneficial for alternative labeling and in the tracking of circulation proangiogenic cells and/or other stem cells in applications of cell therapy through noninvasive magnetic resonance imaging in both preclinical and clinical settings.
\end{abstract}

\section{Introduction}

In the era of cell-based therapy and regenerative medicine, ethical, safe, and efficient treatment protocols are vitally important issues [1-3]. Currently, the magnetic resonance imaging (MRI) of magnetically labeled stem cells represents the only clinically applicable imaging method for highly sensitive, noninvasive, and nonradiation detection protocols. Notably, MRI can be performed serially over time for tracking transplanted stem cells $[1,4,5]$. MRI contrast agents for cell labeling can be used with both T1 and T2 contrast agents, which provide hyperintensity (brightening) and hypointensity (darkening) of T1weighted and T2-weighted images, respectively. Most magnetic resonance imaging probes of labeled stem cells in preclinical and clinical procedures are based on ironbased contrast agents (IBCAs), while superparamagnetic iron oxide nanoparticles (SPIONs) provide negative T2or T2*-weighted images [6]. Multiple characteristics of the nanoparticles determine the labeling efficacy of the agents, including the size of the iron oxide particle, as well as the shape, charge, and nature of the coating result $[7,8]$. These physicochemical characteristics affect not only the efficacy of the particles for MRI but also their stability, 
biodistribution, metabolism, and degree of clearance [9-13]. Currently, iron (III) is an organometallic ion with biocompatibility, which is well known in terms of its biochemistry and homeostasis in living cells and organisms [14]. It has been developed for both T1-positive $[10,15-17]$ and T2-negative $[18,19]$ contrast enhancements. Iron (III) is a d-block transition metal, with five unpaired electrons favoring the formation of six-coordination bonding to the bidentate or tridentate ligands in an octahedral molecular geometrical arrangement [20]. The iron chelators are obtainable by being synthesized or extracted from natural resources for the treatment of iron overload [20, 21] and for imaging probes [15]. To date, dietary flavonoids such as quercetin, rutin, morin, kaempferol, and luteolin have demonstrated potent metal-chelating properties [22-27]. In particular, quercetin has demonstrated strong cardiovascular protection capabilities, anticancer behaviors, and therapeutic activities in both in vitro and in vivo research [28-30]. However, the poor water solubility, chemical instability, and low bioavailability of quercetin can greatly limit its biomedical applications [31]. Determining the metalchelating properties of quercetin, it can be seen that quercetin consists of three phenolic rings including $\mathrm{A}, \mathrm{B}$, and $\mathrm{C}$ rings that are observed in the molecular structure. These rings contain three possible metal-chelating sites that are identified as (1) C3-hydroxy-C4-carbonyl, (2) C4carbonyl-C5-hydroxy, and (3) the ortho-dihydroxyl (catechol) groups [26]. In addition, both the neutral form $(\mathrm{H} 5 \mathrm{QT})$ and the deprotonated forms (H4QT-, $\mathrm{H}_{3} \mathrm{QT}_{2,}$, $\mathrm{H}_{2} \mathrm{QT}_{3-}, \mathrm{HQT}_{4-}$, and $\mathrm{QT}_{5-}$ ) possess levels of potency to chelate metal ions [32]. The complexation of quercetin and a large number of metal ions has been reported. This indicates that the biological activities of this complex are improved and increased compared to those of free quercetin [33-37].

According to our knowledge, the application of an iron (III)-quercetin complex (termed "IronQ") is capable of serving dual purposes as T1 imaging probes for MRI and inducing the circulating proangiogenic cells (CACs) that are derived from peripheral blood mononuclear cells (PBMCs). To date, this CAC growth capability has only been established by our research team [38, 39]. Moreover, the IronQ complex enhances radiation-induced cell death in human erythroleukemic cell lines, doxorubicin-resistant leukemic cells (K562/Adr), and their parental cells (K562) by increasing the generation of intracellular reactive oxygen species (ROS) [40]. However, the chemical structure and chemical properties of IronQ have not yet been established or fully investigated. In the present study, we identified the stoichiometry and synthesis methodology of this complex. Furthermore, we characterized the physicochemical properties and MRI properties of the IronQ, as well as the phenotypic features. The angiogenic potential of circulating proangiogenic cells was also investigated via the induction of PBMCs with IronQ. Moreover, IronQ's labeling efficiency into CACs was determined using an inductively coupled plasma optical emission spectrometer (ICP-OES) in parallel with magnetic resonance imaging at $1.5 \mathrm{~T}$.

\section{Materials and Methods}

2.1. Materials. Quercetin hydrate, HPLC-grade methanol, and iron (III) chloride were purchased from Sigma-Aldrich (MO, USA). Potassium hexacyanoferate (II) trihydrate was purchased from Merck (Darmstadt, Germany). Roswell Park Memorial Institute (RPMI) 1640 medium and fetal bovine serum (FBS) were obtained from Thermo Fisher Scientific (MA, USA). Endothelial Growth Medium-2 Bullet Kit (EGM-2) and Endothelial Basal Medium-2 (EBM-2) were purchased from Lonza (Basel, Switzerland). All chemicals were of analytical grade. Ultrapure water (specific resistivity of $18.2 \mathrm{M} \Omega \cdot \mathrm{cm}$ at $25^{\circ} \mathrm{C}$ ) was prepared using a PURELAB Option-Q system (ELGA LabWater; High Wycombe, UK).

2.2. Determination of Stoichiometry. The method of continuous variations, or Job's method [41], was used to determine the stoichiometry of the metal-ligand complex. In this method, experiments were conducted to establish the complex between iron (III) and quercetin. The stock solution was freshly prepared in $1 \times 10^{-3} \mathrm{M}$ consisting of iron (III) chloride in water and quercetin hydrate in methanol. The quercetin solution was adjusted to a $\mathrm{pH}$ of 12 with $1 \mathrm{M}$ $\mathrm{NaOH}$ before performing the reaction. These two solutions were combined to a total volume of $10 \mathrm{~mL}$ at the following ratios of iron (III):quercetin: $9: 1,4: 1,3: 1,2: 1,1.5: 1,1: 1$, $1: 1.5,1: 2,1: 3,1: 4$, and $1: 9$. The reaction processes were performed at $25^{\circ} \mathrm{C}$ for $2 \mathrm{~h}$. The absorption spectra were then measured using an Agilent 8453 UV-visible spectrophotometer (Agilent Technologies; Santa Clara, California, USA). The complex stoichiometry was determined from the graph, in which the level of absorbance at $480 \mathrm{~nm}$ and the mole fraction of iron (III) to quercetin were plotted.

2.3. Synthesis of the IronQ Complex. Quercetin hydrate $(0.0050$ mole $)$ was added to $500 \mathrm{~mL}$ methanol in round bottles containing an electromagnetic stirrer and a thermometer. The stirred quercetin hydrate was completely dissolved until the color of the solution became yellow. The quercetin hydrate solution was then adjusted to a $\mathrm{pH}$ of 12 by slowly adding a $50 \%(\mathrm{w} / \mathrm{v}) \mathrm{NaOH}$ solution to change the quercetin from a protonated to a deprotonated form. Iron (III) chloride $(0.0025$ mole) in $500 \mathrm{~mL}$ ultrapure water was freshly prepared and mixed with the deprotonated quercetin solution until the color of the solution changed to dark yellow. The reaction of the combined solution was incubated at $60^{\circ} \mathrm{C}$ for $2 \mathrm{~h}$ under continuous stirring. The combined solution was purified by the dialysis method (MWCO: 12000-14000, Cellu SepT3, USA) and then evaporated to dryness using a rotary evaporator, BUCHI Rotavapor R-100 (BÜCHI Labortechnik AG; Flawil, Switzerland). The dark powder product was then collected and stored in a desiccator at room temperature and kept away from the light.

2.4. Characterization and Instruments. The UV-vis absorption spectra of quercetin, deprotonated quercetin, ferric ion, and IronQ were measured in an appropriate solvent 
using $1 \mathrm{~cm}$ quartz cells with a full scan spectrum of 198-1100 nm with an Agilent 8453 spectrophotometer. The IR spectra were determined using the $\mathrm{KBr}$ pellet method in a range of $400-4000 \mathrm{~cm}^{-1}$ on a Nicolet 6700 FTIR spectrometer (Thermo Scientific; MA, USA). The unique crystalline phase of the complex was studied using a Rigaku SmartLab X-ray diffractometer (Rigaku Corporation; Tokyo, Japan) on a copper anode from $2^{\circ}$ to $80^{\circ}$ for the diffraction angles $(2 \theta)$. The morphological investigation was conducted using a field emission scanning electron microscope, JEOL model SEM, JSM-5910LV (JEOL; Tokyo, Japan), operating at $15 \mathrm{kV}$, followed by element analysis via electron-dispersive $\mathrm{X}$-ray spectroscopy (EDS). The particle size of the IronQ was imaged using a transmission electron microscope (TEM), JEOL model JEM-2010, USA, operating at $200 \mathrm{kV}$. Then, TEM images were taken to measure the particle size with the ImageJ software (viable download at https://imagej.nih.gov/ $\mathrm{ij} /$ download.html), and the distribution of the particle size was analyzed using the OriginPro 8 software (Northampton, MA, USA). The hydrodynamic size and zeta potential of IronQ were measured at $25^{\circ} \mathrm{C}$ using folded capillary zeta cells with a Zetasizer Nano ZS (Malvern Panalytical; Malvern, UK). The identification of iron content was confirmed by using a Perkin ELAN-DRCe inductively coupled plasma optical emission spectrometer (Perkin Elmer; MA, USA). The magnetic properties of IronQ were recorded using a vibrating sample magnetometer (VSM).

\subsection{Isolation of Human Peripheral Blood Mononuclear Cells} (PBMCs). Human peripheral blood mononuclear cells (PBMCs) were obtained from the peripheral blood of healthy human donors using the density gradient centrifugation method [38]. The procedures were approved by the Human Research Ethical Committee of the Faculty of Medicine, Chiang Mai University, Thailand (ref. no. NONE2560-05052). Firstly, $60 \mathrm{~mL}$ of whole blood was collected in heparinized tubes (1430 USP units). Furthermore, $15 \mathrm{~mL}$ of whole blood was transferred to a new $50 \mathrm{~mL}$ sterile tube, and then, $15 \mathrm{~mL}$ of phosphate buffer saline (PBS, pH 7.40) was added. Next, the solutions were gently mixed. Subsequently, $15 \mathrm{~mL}$ of Ficoll-hypaque (Lymphoprep ${ }^{\mathrm{TM}}$ ) was carefully injected into the bottom of the tube prior to centrifugation at $1500 \mathrm{rpm}$ for $30 \mathrm{~min}$. The PBMC fraction was then collected from the interphase and washed once with sterile PBS. The cell pellets were then resuspended in a red blood cell (RBC) lysing solution for $5 \mathrm{~min}$. After that, the cells were washed twice with sterile PBS and then resuspended at a density of $1 \times 10^{6}$ cells $/ \mathrm{mL}$ in an RPMI 1640 medium with L-glutamine supplemented with $10 \%$ fetal bovine serum and $1 \%$ penicillin/streptomycin (BioMedia, Singapore). The PBMCs were then cultured at $37^{\circ} \mathrm{C}$ in a humidified atmosphere with $5 \% \mathrm{CO}_{2}$.

2.6. Cell Culture and Treatment for Morphological Observations. Specifically, $1 \times 10^{6}$ cells $/ \mathrm{mL}$ of the PBMC concentration was seeded in 6-well plates with $4 \mathrm{~mL}$ of the RPMI 1640 medium in the presence of 10\% FBS and 1\% penicillin/streptomycin. For the control group, the PBMCs were cultured in the RPMI 1640 medium only. For the experimental group, PBMCs were treated with an RPMI 1640 medium containing $125 \mu \mathrm{g} / \mathrm{mL}$ of the IronQ complex. PBMCs were incubated at $37^{\circ} \mathrm{C}$ in a humidified atmosphere with $5 \% \mathrm{CO}_{2}$ for 14 days. The cell-cultured medium was replaced with $50 \%$ fresh completed medium every 3 days. The cell morphology of the PBMCs was observed daily under an ECLIPSE Ts2 inverted microscope (Nikon; Tokyo, Japan), and the results were recorded using the NIS-Element D software (Nikon; Tokyo, Japan).

\subsection{Peripheral Blood Mononuclear Cell (PBMC) Proliferation} Assay. The 3-(4,5-dimethylthiazol-2yl)-2, 5-diphenyltetrazolium bromide (MTT) colorimetric assay was performed as described previously [42]. Briefly, $1 \times 10^{6}$ PBMCs were suspended in $100 \mu \mathrm{L}$ of the RPMI 1640 medium in the presence of $10 \%$ fetal bovine serum (FBS) and $1 \%$ penicillin/streptomycin and seeded in 96-well plates. Then, IronQ at a final concentration of $125 \mu \mathrm{g} / \mathrm{mL}$ was added and further incubated for the indicated time. The IronQ was evaluated at a final concentration of $125 \mu \mathrm{g} / \mathrm{mL}$ following the primary screening. IronQ was previously tested at serial dilutions ranging from 25 to $1000 \mu \mathrm{g} / \mathrm{mL}$ on PBMC cells. Accordingly, $125 \mu \mathrm{g} / \mathrm{mL}$ of IronQ showed the highest differentiation efficiency without causing toxicity over long-term incubation. After the indicated time point, the supernatants containing IronQ were removed to eliminate the influence of IronQ on the absorption spectra of the formazan solution. After that, the cell pellets were collected and resuspended in $80 \mu \mathrm{L}$ of the RPMI 1640 medium containing $20 \mu \mathrm{L}$ of the $5 \mathrm{mg} / \mathrm{mL}$ solution of MTT, followed by $4 \mathrm{~h}$ incubation. The supernatant in each well was then carefully removed, and $100 \mu \mathrm{L}$ dimethyl sulfoxide (DMSO) was added to dissolve the formazan crystal product in the metabolically viable cells. Absorbance was measured with a BioTekTM EonTM microplate reader (BioTek, USA) at $550 \mathrm{~nm}$.

2.8. Phenotypic Characterization of CACs. The IronQinduced proangiogenic cells were characterized by an immunofluorescent staining assay. Covered glass slides of CACs were fixed with $4 \%$ formaldehyde for $10 \mathrm{~min}$ and blocked by $5 \%$ bovine serum albumin for $1 \mathrm{~h}$ at room temperature. The slides of the CAC cells were then incubated with primary antibodies against CD34, CD14, CD133 (Miltenyi Biotec; CA, USA), CD31, CD45, CD105, and VEGFR-2 (eBioscience; CA, USA) overnight at $4^{\circ} \mathrm{C}$. This step was followed by rinsing the CACs three times with PBS and incubating them with secondary antibodies for $1 \mathrm{~h}$ at room temperature. Finally, the cells were examined under a fluorescence inverted microscope (Nikon; Tokyo, Japan).

2.9. Angiogenesis Assay. The angiogenic potential was tested in the presence of a basement membrane matrix using an in vitro angiogenesis assay kit (Abcam; MA, USA) according to the manufacturer's instructions. Briefly, an extracellular 
matrix solution was placed in a 96 -well plate at $37^{\circ} \mathrm{C}$ for $1 \mathrm{~h}$ to allow the matrix solution to solidify. For the control group, human umbilical vein endothelial cells (HUVECs; ATCC ${ }^{\circledR}$ CRL-1730 ${ }^{\mathrm{TM}}$ ) were seeded onto Matrigel in $5 \times 10^{4}$ cells/well in Dulbecco's modified Eagle's medium with nutrient mixture F-12 (DMEM/F12) supplemented with 20\% FBS (Gibco; USA), $0.1 \mathrm{mg} / \mathrm{mL}$ heparin (Sigma-Aldrich; MO, USA), $5 \mathrm{ng} / \mathrm{mL}$ basic fibroblast growth factor (PeproTech; NJ, USA), and $10 \mathrm{ng} / \mathrm{mL}$ epidermal growth factor (Invitrogen; CA, USA) and incubated for $24 \mathrm{~h}$ to allow for the formation of tubes. To compare the proangiogenic effects of IronQ-induced CACs on endothelial cells, a Matrigel-based capillary-like tube formation assay was performed using the coculturing HUVECs with CACs in the conditioned medium (CM). The IronQ-induced CACs were mixed with HUVECs at a ratio of $1: 2$, seeded in Matrigel, and then, cocultured in a mixture of the CM and HUVEC growth medium $(2: 1, v / v)$. The formed tubules were monitored every $4 \mathrm{~h}$, and cell images were taken with a fluorescence inverted microscope. Cumulative tube length and tube numbers per well were measured using the simple neurite tracer-plugin of Fiji software (http://fiji.sc/ Downloads).

2.10. MRI Phantom Preparation and Relaxivity Measurements. Phantoms of IronQ at various concentrations of 50, 100, 125, $250,500,750$, and $1000 \mu \mathrm{g} / \mathrm{mL}$ were prepared to ultrapure water and human plasma at a final volume of $10 \mathrm{~mL}$ per tube. Additionally, ferric ions $\left(\mathrm{FeCl}_{3}\right)$ at concentrations of $0.1,0.2$, $0.3,0.4$, and $0.5 \mathrm{mM}$ were used to prepare the phantoms. The iron content of IronQ was measured with an ELAN-DRCe Inductively Coupled Plasma-Optical Emission Spectrometer (ICP-OES) (PerkinElmer; MA, USA) to calculate the degree of relaxivity. To avoid the interference of susceptibility artifacts from the surrounding air during the scans, all sample tubes were immersed in a plastic water container and kept at $25^{\circ} \mathrm{C}$. A Philips Ingenia $1.5 \mathrm{~T}$ MRI scanner (Philips; Amsterdam, Netherlands) and the dStream HeadSpine coil were used to establish the imaging phantoms. MR images were analyzed using a Philips DICOM viewer R3.0 SP15 (Philips; Amsterdam, Netherlands). The longitudinal relaxation times ( $\mathrm{T} 1$ values) were measured by imaging the groups of samples simultaneously using an inversion recovery turbo spin echo (IR-TSE) pulse sequence with an echo time (TE) of $40 \mathrm{~ms}$, an echo train length (ETL) of 5, a repetition time (TR) of $1000 \mathrm{~ms}$, an inversion time (TI) of $50-700 \mathrm{~ms}$ (interval of $50 \mathrm{~ms}$ ), an average (NSA) of 2 , and a sliced thickness of $3 \mathrm{~mm}$. The transversal relaxation times (T2 values) were measured by imaging the same samples as indicated above using a turbo spin echo (TSE) pulse sequence with a TR of $3000 \mathrm{~ms}$; variable TE values of 50, 75, $100,125,150,200,250$, and $350 \mathrm{~ms}$; an ETL of 16; an NSA of 5 ; and a sliced thickness of $3 \mathrm{~mm}$.

The T1-longitudinal relaxivity $(\mathrm{r} 1)$ and $\mathrm{T} 2$-transversal relaxivity ( $\mathrm{r} 2$ ) of IronQ were evaluated using the linear equation [15] as follows:

$$
\frac{1}{T(1,2)}=\frac{1}{T(1,2)_{0}}+r(1,2) \times[\operatorname{Iron} Q],
$$

where $T(1,2)$ represents the measured $T 1$ or $T 2$ time of the solution containing the IronQ and $T(1,2)_{0}$ represents the $T 1$ or T2 time of the blank matrix (human plasma or DI). The degree of relaxivity was obtained from the slope of the linear fit of the abovementioned equation with a representative unit in $\mathrm{mM}^{-1} \mathrm{~s}^{-1}$.

2.11. PBMC Labeling and In Vitro MR Imaging. Subsequently, $5 \times 10^{5}$ cells $/ \mathrm{mL}$ in $10 \mathrm{~mL}$ of PBMC were cultured in T-25 $\mathrm{cm}^{2}$ culture flasks in an RPMI 1640 medium containing IronQ at concentrations of $0,25,50,100$, and $200 \mu \mathrm{g} / \mathrm{mL}$ in a humidified $\mathrm{CO}_{2}$ incubator at $37^{\circ} \mathrm{C}$ for 1 and 10 days. After the indicated periods of time, the IronQlabeled cells and adherent cells were washed three times with PBS to remove any unbounded IronQ from the cells. Labeled PBMCs were harvested via trypsinization (0.25\% trypsin, $5 \mathrm{~min}$ at $37^{\circ} \mathrm{C}$ ), resuspended in PBS, and counted using a hemocytometer. Next, $5 \times 10^{6}$ cells were transferred to $1.5 \mathrm{~mL}$ microcentrifuge tubes and spun down by centrifugation at $7000 \mathrm{rpm}$ for $30 \mathrm{sec}$ for further imaging by MRI. The sample tubes were placed in a plastic rack with dimensions of $18.5 \mathrm{~cm} \times 12.5 \mathrm{~cm} \times 6.5 \mathrm{~cm}$ and fixed in a water bath to produce a phantom. This phantom was placed carefully in the center of a dStream HeadSpine coil to perform T1-weighted imaging using a Philips Ingenia $1.5 \mathrm{~T}$ MRI scanner. PMBC-labeled cells were imaged using the spin echo sequence (SE) with parameters of $\mathrm{TE} / \mathrm{TR}=11$ / $525 \mathrm{~ms}$, a flip angle $=69^{\circ}$, a field of view $(\mathrm{FOV})=230 \mathrm{~mm}$, a matrix value $=512 \times 512$, slice thickness $=3 \mathrm{~mm}$, and $\mathrm{NSA}=2$. The signal intensity of the sagittal image was measured by employing the region of interest (ROI) technique and using a Philips DICOM viewer R3.0 SP15.

2.12. Determination of PBMC Labeling Efficiency by Prussian Blue Assay. To verify the intracellular IronQ uptake of the PBMCs, Prussian blue dye was used to stain the iron component. PBMC $\left(1 \times 10^{6}\right.$ cells $\left./ \mathrm{mL}, 5 \mathrm{~mL}\right)$ cells in a 6 -well plate were incubated with or without $125 \mu \mathrm{g} / \mathrm{mL}$ IronQ for 10 days. After that time, the culture medium containing free IronQ outside the cells was removed, and the PBMCs were washed three times with PBS. Next, the cells were fixed with $4 \%$ paraformaldehyde at $37^{\circ} \mathrm{C}$ in a humidified incubator with $5 \% \mathrm{CO}_{2}$ for $20 \mathrm{~min}$. After that, a fixative reagent was removed, and $10 \%$ potassium ferrocyanide in $6 \%$ hydrochloric acid was continuously added at a final volume $1 \mathrm{~mL}$. The cells were then reincubated at $37^{\circ} \mathrm{C}$ for $30 \mathrm{~min}$. After the indicated time, the cell morphology and positively blue-stained cells were observed under an inverted microscope and imaged.

2.13. Intracellular Cellular Content of IronQ. Specifically, $5 \times 10^{5}$ cells $/ \mathrm{mL}$ in $10 \mathrm{~mL}$ of PBMCs were cultured in $\mathrm{T}-25 \mathrm{~cm}^{2}$ culture flasks containing IronQ at concentrations of $0,25,50,100$, and $200 \mu \mathrm{g} / \mathrm{mL}$ in a humidified $\mathrm{CO}_{2}$ incubator at $37^{\circ} \mathrm{C}$ for 1 and 10 days. After the indicated periods of time, the IronQ-labeled cells and adherent cells were washed three times with PBS to remove any unbounded IronQ from the cells. Labeled PBMCs were harvested by 
trypsinization $\left(0.25 \%\right.$ trypsin, $5 \mathrm{~min}$ at $\left.37^{\circ} \mathrm{C}\right)$, resuspended in PBS, and counted using a hemocytometer. The cells were collected by centrifugation at $7000 \mathrm{rpm}$ for $1 \mathrm{~min}$. After that, the cell pellets were resuspended in $5 \mathrm{~mL}$ of $20 \% \mathrm{HNO}_{3}$ solution and incubated at $60^{\circ} \mathrm{C}$ for $6 \mathrm{~h}$ under a fume hood. The samples were then evaluated for their iron contents with ICP-OES. This experiment was conducted in triplicate on each day of the experiment.

2.14. Statistical Analysis. Data were expressed as mean\pm standard deviation values. Statistical differences were assessed using a one-way ANOVA test followed by Tukey's multicomparison for the two groups in the experiment. Notably, $p<0.05$ was indicative of any statistical significant differences.

\section{Results and Discussion}

3.1. Stoichiometry Determination. The method of continuous variation was used to validate the stoichiometric composition of the iron (III)-quercetin complex in a watermethanol solvent system. Iron (III) and quercetin at a concentration of $1 \times 10^{-3} \mathrm{M}$ were mixed in equimolar proportions to form the products at different ratios varying from $1: 9$ to $9: 1$. The results are shown in Figure 1. The colors of the chemical reaction products ranged from light brown to dark brown (inset of Figure 1). This corresponded to increasing molar fractions of quercetin as the color turned back to pale brown after passing through a solution with an appropriate ratio of iron (III) and quercetin. The proper ratio of iron (III) and quercetin was indicated at $1: 2$, as this is the ratio at which the desired precipitation of the specified products occurred (brownish-black). This result is similar to that of the spectrophotometric result after investigating the UV-visible absorption band of the complex at $480 \mathrm{~nm}$, which revealed a maximum level of absorbance at 0.667 of the mole fractions for quercetin (Figure 1). The experiment using Job's method indicated a stoichiometric ratio for the reaction between 1:2 iron (III) and quercetin in a watermethanol solvent system at an alkaline $\mathrm{pH}$ value. Much research indicates that quercetin is a strong chelating agent that can chelate divalent (e.g., Zn (II), Fe (II), Co (II), Ni (II), and $\mathrm{Cu}$ (II)) and trivalent (e.g., Fe (III), Sb (III), Ga (III), and Gd (III)) metallic ions at different stoichiometric ratios of 1 : $1,1: 2,1: 3,2: 1$, and $2: 3$ for Metal:Quercetin [23-26, 43-47]. Among the metal ions, iron (II) and iron (III) ions favor being chelated by two molecules of quercetin at ratios $1: 2$ and $1: 1$, respectively $[43,48]$. However, there are many factors in the experimental conditions that contribute to the formation of a metal-ligand complex, e.g., $\mathrm{pH}$ values, oxidizing agents, reactant forms, and solvent systems [49].

3.2. Spectroscopic Characterization. The electronic absorption spectra of the iron (III)-quercetin complex, quercetin, and the deprotonated quercetin were identified using UV-vis spectrophotometry. These recorded spectra are shown in Figure 2(b). The absorption spectra of quercetin in methanol

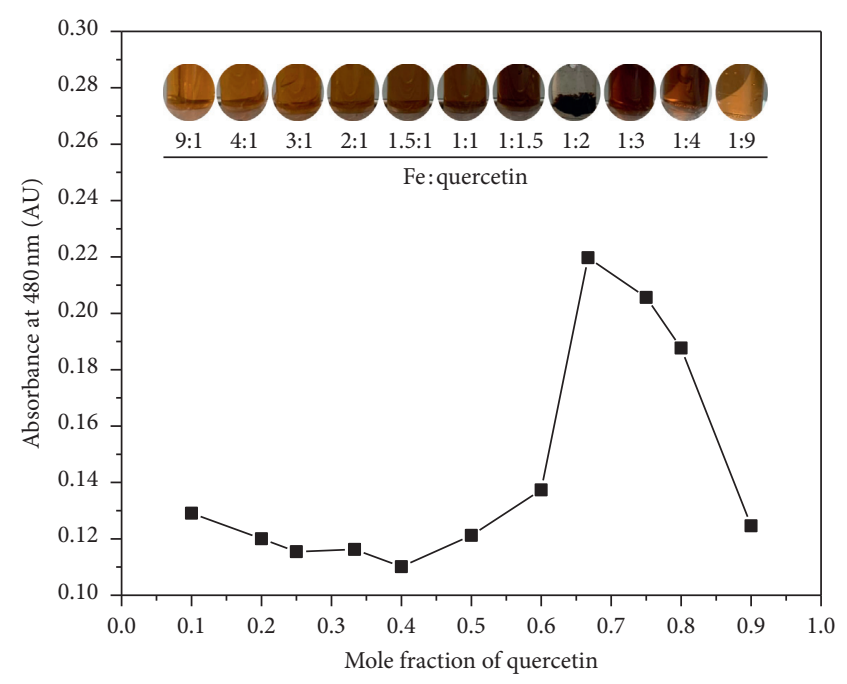

FIGURE 1: Determination of the stoichiometry of ironQ using Job's method to plot the absorbance at $480 \mathrm{~nm}$ and the mole fraction of quercetin. The inset in Job's plot is representative of a photograph of each reaction product.

appeared as two major absorption bands at 372 (band I) and 256 (band II) nm, which corresponded to the bands of the cinnamoyl system and benzoyl system, respectively [50]. Quercetin (H5QT) contained five hydroxyl groups $(-\mathrm{OH})$ that were ionizable at different dissociation constant $(\mathrm{pKa})$ values (Figure 2(a)). The order of deprotonation was found to be $\mathrm{C}_{4^{\prime}}-\mathrm{OH}, \mathrm{C} 7-\mathrm{OH}, \mathrm{C}_{3}-\mathrm{OH}, \mathrm{C}_{3^{\prime}}-\mathrm{OH}$, and $\mathrm{C}_{5}-\mathrm{OH}$, with $\mathrm{pKa} 1=6.41, \mathrm{pKa} 2=7.81, \mathrm{pKa} 3=10.19, \mathrm{pKa} 4=11.53$, and $\mathrm{pKa} 5=12.91$, respectively $[32,51]$. The titration of quercetin supplemented with $\mathrm{NaOH}$ resulted in deprotonated formation (H4QT ${ }^{-}, \mathrm{H}_{3} \mathrm{QT}^{2-}, \mathrm{H}_{2} \mathrm{QT}^{3-}, \mathrm{HQT}^{4-}$, and $\mathrm{QT}^{5-}$ ), while an increase in the $\mathrm{pH}$ values resulted in a bathochromic shift of the electronic absorption spectrum of quercetin. At a $\mathrm{pH}$ value of 12, the major deprotonated form of quercetin, $\mathrm{HQT}^{4-}$ (deprotonated by $4 \mathrm{H}^{+}$), was present at $70 \%$. Consequently, absorbance peaks were observed at 256, 290 , and $340 \mathrm{~nm}$. It has been shown that quercetin can be deprotonated by the specific oxidation of the -OH groups at the catechol site with a shift base agent (sodium methoxide) in the presence of free $-\mathrm{OH}$ groups at $\mathrm{C}_{3}$ on ring $\mathrm{C}$ and at $\mathrm{C}_{7}$ on ring $\mathrm{A}$, which are known to be responsible for electronic absorption peaks recorded at $348 \mathrm{~nm}$ (band I) and $300 \mathrm{~nm}$ (band II), respectively $[32,52,53]$. As mentioned above, an absorption peak of $256 \mathrm{~nm}$ represents the free -OH group at $\mathrm{C}_{5}$ on ring $\mathrm{A}$. Taken together, the occurrence of oxidation of the $-\mathrm{OH}$ groups via the addition of $\mathrm{NaOH}(\mathrm{pH} 12$ final) is possible at the positions of $\mathrm{C}_{4^{\prime}}, \mathrm{C}_{7}, \mathrm{C}_{3}$, and $\mathrm{C}_{3^{\prime}}$ in the quercetin structure (Figure $2(\mathrm{a})$ ). In fact, at the beginning, a $\mathrm{pH}$ value of 12 was reached, and an absorbance peak was observed, at $420-425 \mathrm{~nm}$. Subsequently, this peak disappeared over a short period of time as an expected result of the condensation or polymerization between each form of quinones $[32,54]$. The absorption peaks of IronQ in water were observed at $290 \mathrm{~nm}$ and $450-700 \mathrm{~nm}$. By comparing the absorption spectrum of IronQ to that of the deprotonated quercetin, the peak of $256 \mathrm{~nm}$ disappeared $\left(\mathrm{C}_{5}=\mathrm{O}\right)$, while the 


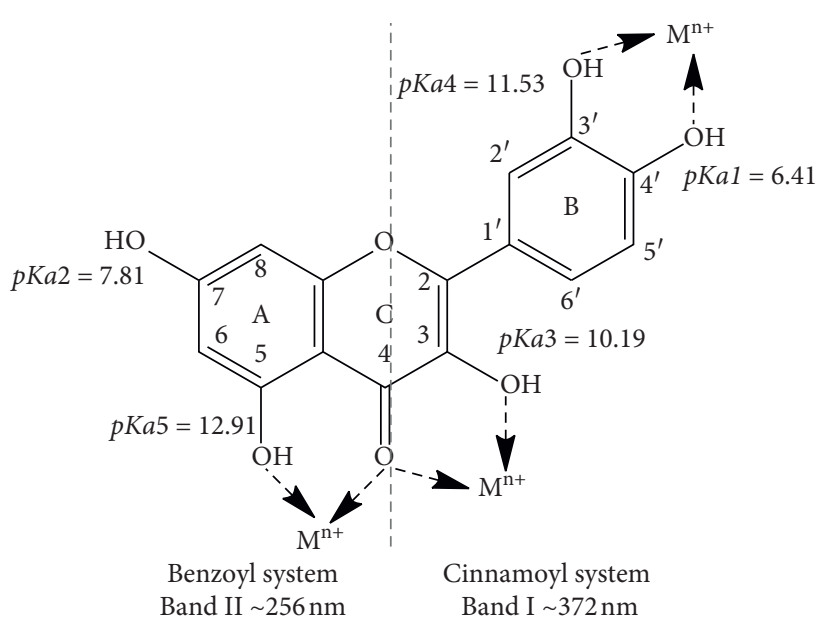

Benzoyl system
Band I $\sim 372 \mathrm{~nm}$

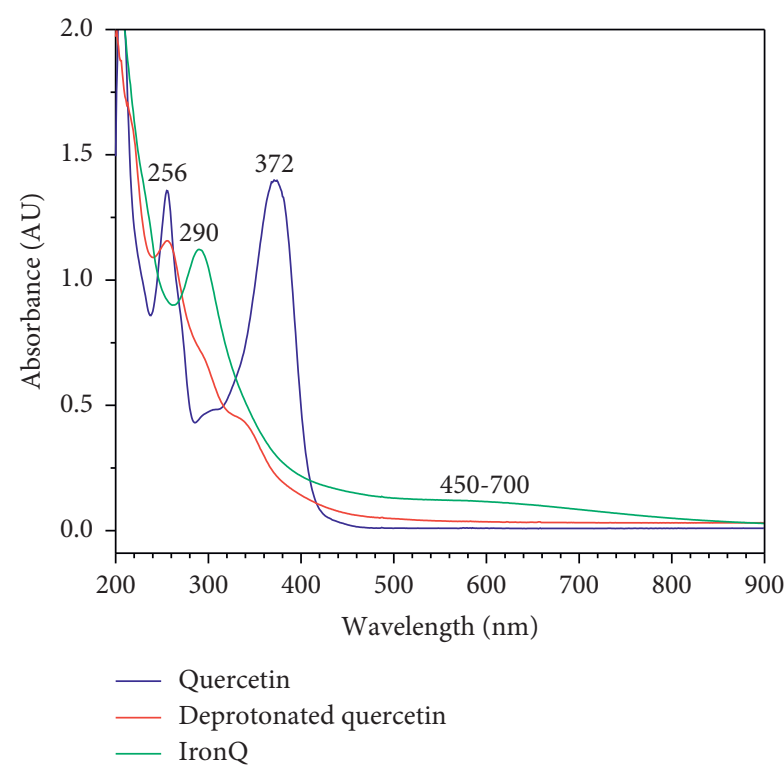

(b)

Figure 2: (a) Molecular structure, pKa values, and the favored metal-chelating sites of quercetin; (b) UV-visible spectra of quercetin, deprotonated quercetin, and IronQ. $\mathrm{Mn}^{+}=$metal cation with the oxidation state of $n$.

peak of $290 \mathrm{~nm}\left(\mathrm{C}_{7}-\mathrm{OH}\right)$ for the degree of absorption intensity increased. Notably, a level of absorbance of $420 \mathrm{~nm}$ still appeared on the shoulders ( $\mathrm{Fe}-\mathrm{O}$ complex at the positions of $\mathrm{C}_{3}=\mathrm{O}$ and $\left.\mathrm{C}_{4}-\mathrm{OH}\right)$, and a new absorption broadband at 450-700 $\mathrm{nm}$ was observed ( $\mathrm{Fe}-\mathrm{O}$ complex at the catechol sites, $\mathrm{C}_{3^{\prime}}=\mathrm{O}$ and $\left.\mathrm{C}_{4^{\prime}}=\mathrm{O}\right)[22,55,56]$.

As stated in the published literature, the UV-vis spectrum of the complex of iron (III) with quercetin can be identified by its characteristic absorption peaks at 290-294, 420-430, and 450-700 nm depending on the environmental conditions and the stoichiometry of the complex formation [55]. The complex of iron (III) with quercetin under acidic conditions of pH 2 in methanol-water revealed major absorption bands at $420 \mathrm{~nm}$ and $700 \mathrm{~nm}$, which were ascribed to the formations of $1: 1$ and $2: 1$ iron (III): quercetin complexes, respectively $[22,54]$. It was reported that the chemical reaction of iron (III) at the catechol site of gallic acid, gallic acid methyl ester, and catechin resulted in characteristic absorption peaks of $415 \mathrm{~nm}$ and $690-695 \mathrm{~nm}$ [57], while the chemical reaction of iron (III) at the hydroxychromone site of quercetin revealed an absorption peak of $420 \mathrm{~nm}$ [22]. On the other hand, the complex of $\mathrm{Gd}$ (III)-quercetin, whose complex site is located at $\mathrm{C}_{4}$ on ring $\mathrm{C}$ and $\mathrm{C}_{5}$ on ring $\mathrm{A}$ of quercetin, did not reveal an absorption peak at a wavelength higher than $450 \mathrm{~nm}$ [46]. The complex between iron (III) and 3, 5, 7-tri-O-methyl-quercetin (free $-\mathrm{OH}$ at the catechol site) revealed a characteristic absorption peak of $600 \mathrm{~nm}$ [58]. In this study, the formation of the ferric hydroxide $\left(\left(\mathrm{Fe}(\mathrm{OH})_{3}\right)\right.$, a typical precipitate formed in an aqueous solution at $\mathrm{pH}$ values ranging from 7.0 to 9.0, was not observed [59]. To identify the interaction between the deprotonated quercetin and IronQ, the FTIR spectra, and characteristic bands of pure quercetin, the deprotonated quercetin and IronQ were compared, as shown in Figure 3 and Table 1 [60-62]. We observed that the aryl ketonic stretching $\mathrm{C}_{4}=\mathrm{O}$ at $1664 \mathrm{~cm}^{-1}$ of quercetin disappeared, while new strong $\mathrm{C}=\mathrm{C}$ stretching bands at $1592 \mathrm{~cm}^{-1}$ and $1569 \mathrm{~cm}^{-1}$ appeared for deprotonated quercetin and IronQ, respectively $[52,53]$. The results suggest that as the deprotonation of $\mathrm{C}_{3}-\mathrm{OH}$ occurred, an intrastructure rearrangement resulted in, at least, two resonance aryl ketones $\left(\mathrm{OC}_{3}=\mathrm{C}_{4} \mathrm{O}^{-}\right)$in their molecules being affected by the loss of the $\mathrm{C}_{4}=\mathrm{O}$ stretching signal. Indeed, the delocalization of electrons clearly occurred on rings $\mathrm{A}, \mathrm{B}$, and $\mathrm{C}$ of the deprotonated quercetin. The deprotonation of the hydroxyl groups of quercetin reflected a loss of C-O-H stretching at $1196 \mathrm{~cm}^{-1}$, and the regression signal of $\mathrm{O}-\mathrm{H}$ bending of the phenols was observed. On the other hand, C-O stretching in the phenol was not observed in the deprotonated quercetin or IronQ. The presence of C-O-C stretching was found in all three samples, while quercetin, the deprotonated quercetin, and iron (III)-quercetin demonstrated that the basic structure of quercetin was not broken. For IronQ, only one new band at $470 \mathrm{~cm}^{-1}$ appeared and was ascribed to $\mathrm{Fe}-\mathrm{O}$ stretching for the Fe (III)-quercetin complex, but in the case of the Fe (II)-quercetin complex, Fe-O stretching was found at a higher wavenumber shift than $630 \mathrm{~cm}^{-1}[48,63]$. Notably, this confirmed the formation of the iron (III)quercetin complex. Together with the UV-visible, NMR, and FTIR results, two sites at $\mathrm{C}_{3^{\prime}}-\mathrm{O}-/ \mathrm{C}_{4^{\prime}}-\mathrm{O}$ - on ring $\mathrm{B}$ and $\mathrm{C}_{3^{-}}$ $\mathrm{O}-/ \mathrm{C}_{4}=\mathrm{O}$ on ring $\mathrm{C}$ of the deprotonated quercetin molecules $\left(\mathrm{HQT}^{4-}\right.$ and $\mathrm{QT}^{5-}$ ) (Figure 4(a)) were involved in the formation of IronQ (as loss of their stretching signals) with a stoichiometry ratio of $1: 2$ for iron (III) and quercetin, respectively. Oxygen atoms at these sites acted as electron donors to form coordinated covalent bonding with iron (III), and two molecules of water $(q=2)$ were also involved in the hexa-coordinated complex [20]. The proposed 


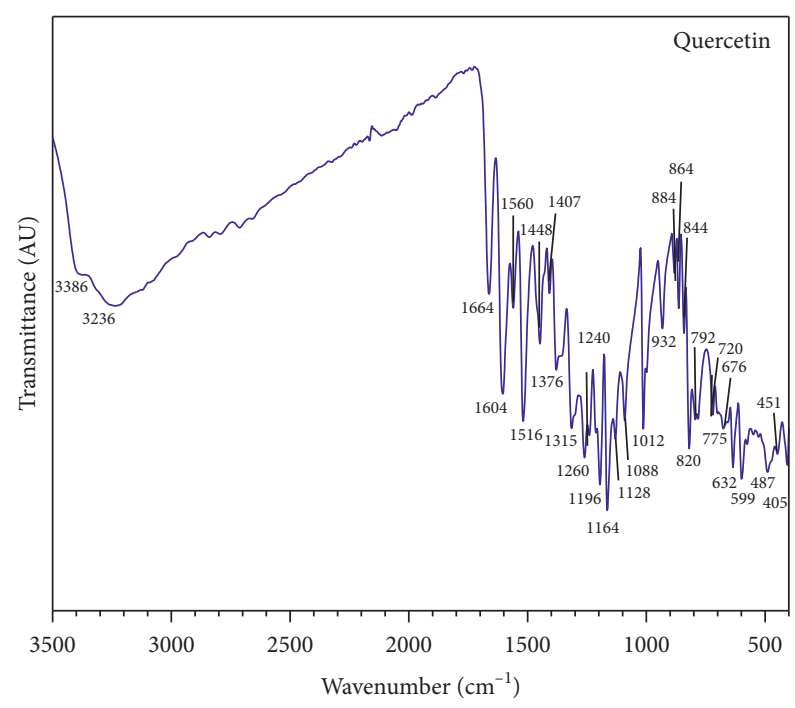

(a)

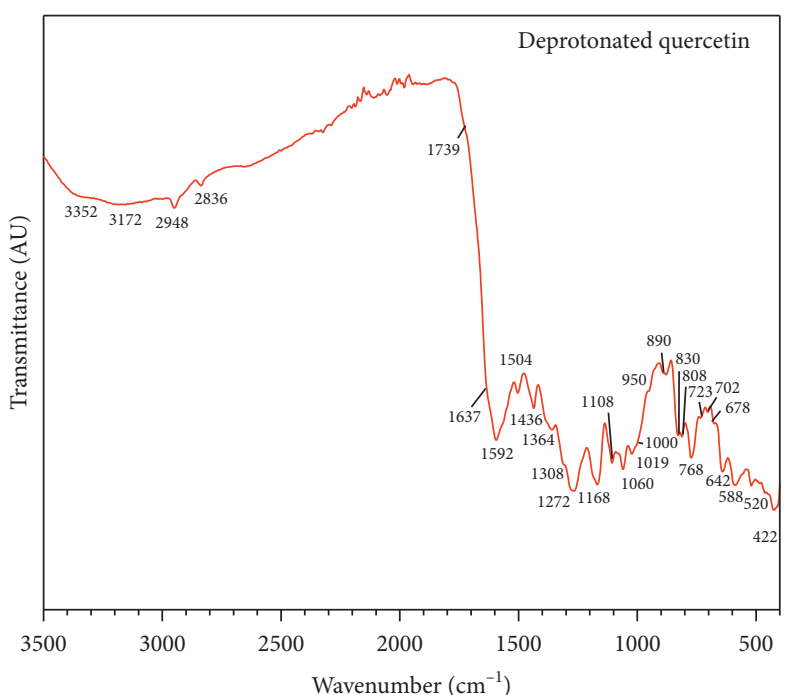

(b)

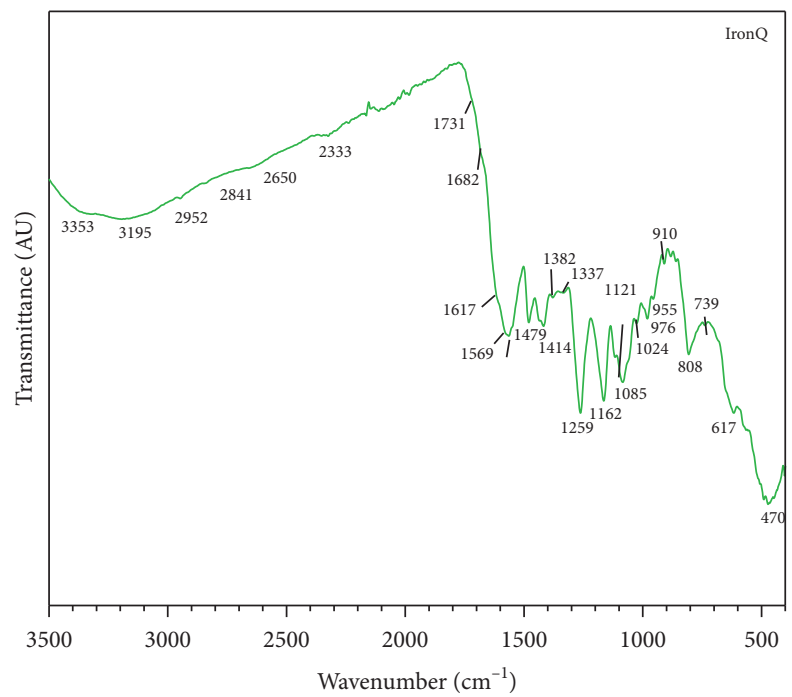

(c)

FIGURE 3: FTIR spectra of (a) quercetin, (b) the deprotonated quercetin, and (c) IronQ.

TABLE 1: FTIR information regarding the detected characteristic bands [60-62] of quercetin, the deprotonated quercetin, and IronQ.

\begin{tabular}{|c|c|c|c|}
\hline \multirow{2}{*}{ Group assigned to the given band } & \multicolumn{3}{|c|}{ Wavenumber $\left(\mathrm{cm}^{-1}\right)$} \\
\hline & Quercetin & Deprotonated quercetin ( $\mathrm{pH} \mathrm{12)}$ & IronQ \\
\hline $\mathrm{O}-\mathrm{H}$ stretching vibration of phenol & 3386,3263 & 3352,3172 & 3353,3195 \\
\hline $\mathrm{C}=\mathrm{O}$ aryl ketonic stretch & $1664 \mathrm{~s}$ & $1637 \mathrm{w}, 1739 \mathrm{w}$ (shoulders) & $\begin{array}{l}1617 \mathrm{w}, 1682 \mathrm{w}, 1731 \mathrm{w} \\
\text { (shoulders) }\end{array}$ \\
\hline $\mathrm{C}=\mathrm{C}$ aromatic ring stretching bands & 1604 s, 1560 s, 1516 s, 1448 s, 1407 s & $1592 \mathrm{~s}, 1504 \mathrm{w}, 1436 \mathrm{~m}$ & $1569 \mathrm{~s}, 1479 \mathrm{~s}, 1414 \mathrm{~s}$ \\
\hline $\mathrm{O}-\mathrm{H}$ bending of phenols & $1376 \mathrm{~s}$ & $1364 \mathrm{w}$ & $1382 \mathrm{w}$ \\
\hline $\begin{array}{l}\mathrm{C}-\mathrm{H} \text { bonds in aromatic } \\
\text { hydrocarbon bending (in-plane) }\end{array}$ & $1315 \mathrm{~s}, 1128 \mathrm{~s}, 1088 \mathrm{~s}, 1012 \mathrm{~s}, 932 \mathrm{~s}$ & $\begin{array}{c}1308 \mathrm{w} \text { (shoulder), } 1108 \mathrm{~m}, \\
1060 \mathrm{~m}, 1019 \mathrm{~m}, 950 \mathrm{w}\end{array}$ & $\begin{array}{l}1337 \mathrm{w}, 1121 \mathrm{w}, 1085 \mathrm{~s} \\
1024 \mathrm{w}, 976 \mathrm{~m}, 955 \mathrm{w}\end{array}$ \\
\hline $\begin{array}{l}\mathrm{C}-\mathrm{O} \text { stretching of aryl ether } \\
(\mathrm{C}-\mathrm{O}-\mathrm{C})\end{array}$ & $1260 \mathrm{~s}$ & $1272 \mathrm{~s}$ & $1259 \mathrm{~s}$ \\
\hline $\mathrm{C}-\mathrm{O}$ stretching in phenol & $1196 s$ & - & - \\
\hline $\begin{array}{l}\mathrm{C}-\mathrm{CO}-\mathrm{C} \text { stretching and bending in } \\
\text { ketones }\end{array}$ & $1164 \mathrm{~s}$ & $1168 s$ & $1162 \mathrm{~s}$ \\
\hline $\begin{array}{l}\mathrm{C}-\mathrm{H} \text { bending of aromatic } \\
\text { hydrocarbons (out-of-plane) }\end{array}$ & $\begin{array}{c}884 \mathrm{~s}, 864 \mathrm{~s}, 844 \mathrm{~s}, 820 \mathrm{~s}, 795 / 792 \mathrm{w} \\
720 \mathrm{~s}, 676,632 \mathrm{~s}, 599 \mathrm{~s}\end{array}$ & $\begin{array}{c}890 \mathrm{w}, 830 / 808 \mathrm{w}, 768 \mathrm{~s}, 678 \mathrm{w}, \\
642 \mathrm{~s}, 588 \mathrm{~m}\end{array}$ & 910 w, 808 s, 739 w, $617 \mathrm{~m}$ \\
\hline Fe-O stretching & - & - & $470 \mathrm{~s}$ \\
\hline
\end{tabular}

Note. $\mathrm{s}=$ strong, $\mathrm{m}=$ moderate, $\mathrm{w}=$ weak. 
<smiles>O=c1c(O)c(-c2ccc(O)c(O)c2)oc2cc(O)cc(O)c12</smiles>

(a)

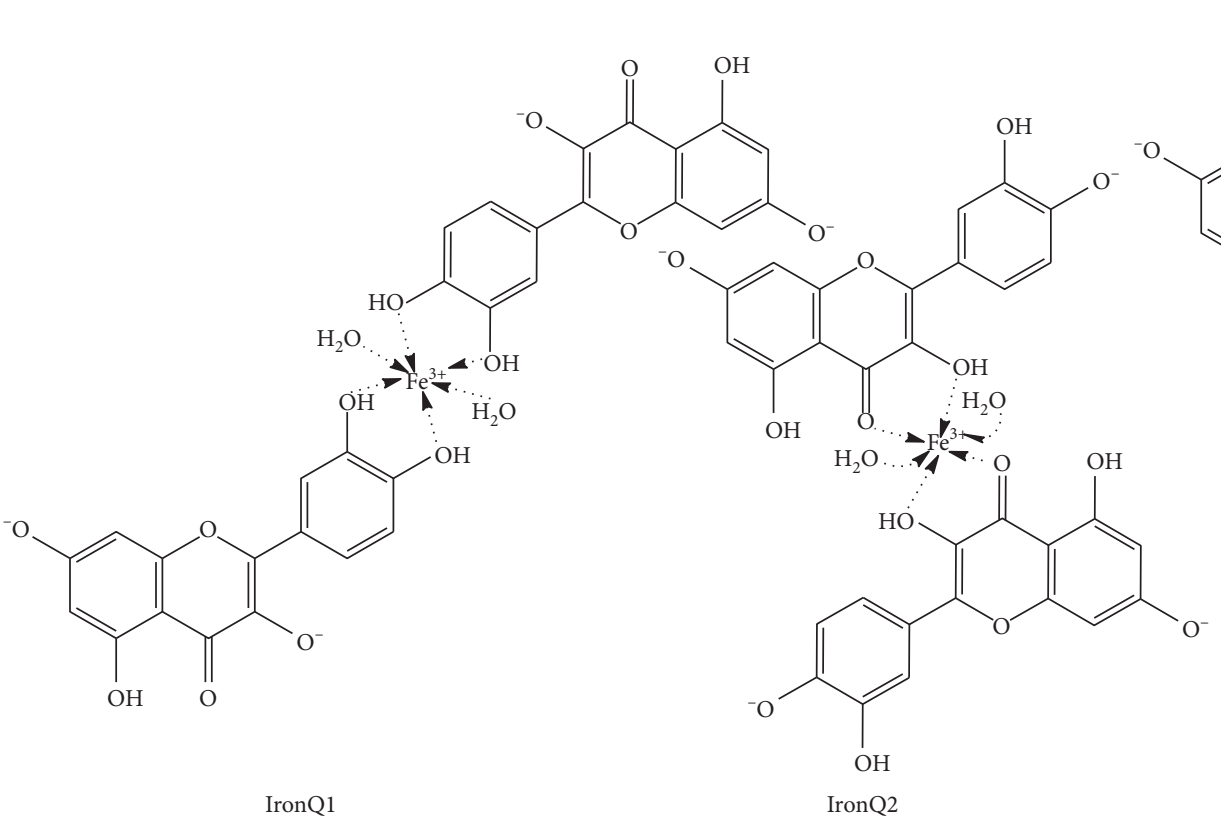<smiles></smiles>

(b)

FIGURE 4: (a) Quercetin deprotonation products observed at a pH value of 12 and (b) the three proposed structures of the iron (III)quercetin complex.

structures of IronQ at an adjusted $\mathrm{pH}$ value of 7.40 are indicated in Figure 4(b). The hydration molecules $(q)$ of the metal core (i.e., $\mathrm{Gd}^{3+}, \mathrm{Mn}^{2+}$, and $\mathrm{Fe}^{3+}$ ) directly resulted in the relaxivity of the contrast agent, while the conventional $\mathrm{Gd}^{3+}$-based contrast agents presented only one hydration molecule $(q=1)[64,65]$. The two hydration molecules of IronQ involving $\mathrm{Fe}^{3+}$ induced a dipole-dipole interaction, leading to a shortening of $\mathrm{Tl}$, which resulted in a contrast enhancement on the T1-weighted images [66].

The ${ }^{1} \mathrm{H}$-NMR spectra were recorded for quercetin, the deprotonated quercetin, and IronQ at $500 \mathrm{MHz}$ (See Figures S1-S3 in the Supplementary Materials). In the case of IronQ, the NMR profile displayed a similar pattern to the deprotonated quercetin, but broad-spectrum and low-level signals were also detected. In addition, two new multiplets (at $\delta=2.37 \mathrm{ppm}$ and $\delta=2.77 \mathrm{ppm}$ ) were observed. X-ray powder diffraction (XRD) was used for unique phase determination of the IronQ, and information was provided on the crystalline or amorphous material. The chemical compositions of quercetin, quercetin quinone, and IronQ were established by XRD patterns from $2^{\circ}$ to $80^{\circ}$, as shown in
Figure 5. The diffractograms of quercetin as quercetin dihydrate revealed a series of intense peaks that were representative of the physicochemical properties [67], while quercetin quinone tended to display an amorphous pattern. Furthermore, the results present a broad XRD pattern for IronQ with no diffraction peak, indicating an amorphous nature.

3.3. Particle Morphology and Elemental Analysis. The particle morphology of IronQ was observed using a field emission scanning electron microscope (SEM). The SEM images of quercetin and IronQ were used to evaluate the geometrical shape parameters of the particles. The SEM images of quercetin displayed rod-like or needle-like shapes (Figure 6(a)). In contrast, IronQ showed a smooth surface and an amorphous nature (Figures 6(b) and 6(c)). The element profiles on the surface of the IronQ were analyzed by energy-dispersive X-ray (EDX) spectroscopy. The EDX spectrum of the IronQ, as shown in Figure 6(d), revealed that the compositions of $\mathrm{C}, \mathrm{O}, \mathrm{Na}$, and $\mathrm{Fe}$ were $46.57 \%$, 


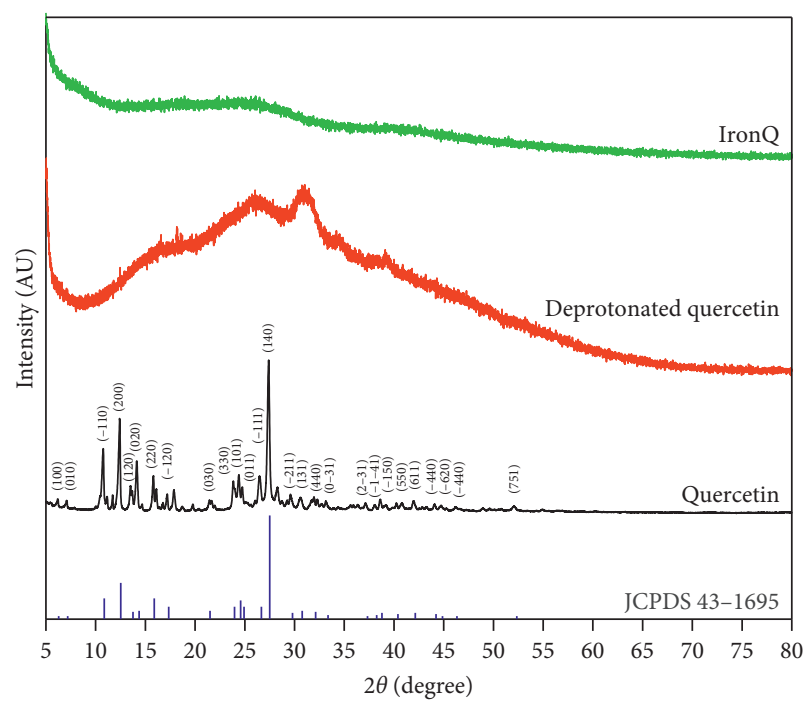

FIGURE 5: Powder XRD patterns of quercetin, the deprotonated quercetin, IronQ, and the standard quercetin (JCPDS Card No. 43-1685).

$37.29 \%, 13.07 \%$, and 3.07\%, respectively. A Na atom was introduced by $\mathrm{NaOH}$ titration and might ionically bond with the Iron $\mathrm{Q}$ at free -C-O- moieties of deprotonated quercetin. This atom was also found to stabilize the complex, as shown in the sodium salt formula. These sodium ions are involved in making ionic bonding to the four deprotonated $\left(\mathrm{C}-\mathrm{O}^{-}\right)$ positions on the IronQ structure, as shown in Figure 4(b).

3.4. Particle Size and Zeta Potential Analysis. The morphology and particle sizes of IronQ were characterized using a transmission electron microscope (TEM). The TEM images of IronQ showed spherical shapes of various sizes. The distribution of their sizes ranged from 37 to $600 \mathrm{~nm}$, and the mean and median sizes of the particles were 131.92 and $81.39 \mathrm{~nm}$, respectively (Figures 7 (a) and $7(\mathrm{~b})$ ). However, the aggregation of the complex was found with a larger spherical shape and size approaching $\sim 600 \mathrm{~nm}$, while the hydrodynamic diameter (HDD) of the IronQ in ultrapure water, which was adjusted to a pH of 7.4 at $25^{\circ} \mathrm{C}$ using the dynamic light scattering (DLS) technique, was observed with an average size of $160.0 \pm 2.4 \mathrm{~nm}$ (Figure $7(\mathrm{c})$ ). In addition, IronQ displayed a negative charge on its surface with the mean zeta potential of $-24.53 \pm 1.88 \mathrm{mV}$ (Figure $7(\mathrm{~d})$ ). The zeta potential value less than $-30 \mathrm{mV}$ indicates that IronQ had moderate stability in water; thus, agglomerations could be observed, as shown in Figure 7(d) [68]. The negative zeta potential values indicate that the surface of IronQ has anionic charges; this property generally improves the blood circulation half life of the complex through electrostatic repulsive force with plasma proteins. This outcome reduced the level of protein adsorption and phagocytosis by the reticuloendothelial system (RES) [7, 69, 70].

3.5. Magnetic Properties and Phantom MRI Analysis. The magnetic property of iron (III)-quercetin was determined by the saturation magnetization (Ms) obtained from the $\mathrm{M}-\mathrm{H}$ curve using VSM, as indicated in Figure 8. The obtained value was found to be $0.155 \mathrm{emu} / \mathrm{g}$ at $1.0 \mathrm{~T}(10 \mathrm{kOe})$, indicating that this complex has paramagnetic properties. The lower-level values of the saturation magnetization of IronQ were responsible as a T1-positive contrast (bright image) agent for magnetic resonance imaging (MRI). T1-positive contrast agents, such as gadopentetate dimeglumine (Magnevist ${ }^{\circledR}$ ), revealed Ms values equal to $0.397 \mathrm{emu} / \mathrm{g}$ at $1.2 \mathrm{~T}(12 \mathrm{kOe})$, while the $\mathrm{Gd}$ (III)-quercetin complex revealed $\mathrm{Ms}$ values equal to $0.405 \mathrm{emu} / \mathrm{g}$ at $1.5 \mathrm{~T}$, and the iron (III)-doped calcium phosphate nanoparticles revealed Ms values that were lower than $0.15 \mathrm{emu} / \mathrm{g}$ at $1.5 \mathrm{~T}$ [71-73]. Notably, the higher levels ( $>20 \mathrm{emu} / \mathrm{g}$ ) of the contrast agents, particularly superparamagnetic iron oxide nanoparticles (SPIONs), were observed as a superparamagnetic property and exhibited T2 negative (contrast dark image) in MR imaging [71, 74]. However, the ultrasmall iron oxide nanoparticles $(<6 \mathrm{~nm})$ displayed the properties of the T1contrast agent $[10,75]$. Indeed, both the T1 (spin-lattice interaction) and $\mathrm{T} 2$ (spin-spin interaction) relaxations of the contrast agents were dependent upon the saturation magnetization of the nanoparticles, their magnetic interactions with the protons of the surrounding water molecules, and their magnetic strength.

The paramagnetic properties of IronQ in the case study may be related to the five unpaired electrons found in the $3 \mathrm{~d}$ orbit of iron (III) (high spin, $S=5 / 2$ ), leading to an apparent effect identified as spin-lattice interactions under longitudinal relaxation at the applied magnetic field [73]. However, the oxidative state of iron (II) without the magnetic property did not affect T1 relaxation. Numerous iron (III) complexes with small molecules beyond quercetin were representative of a T1-positive contrast agent, such as + Fe-DTPA, FetCDTA, Fe-HBED, and Fe-3FCAT 3 [15-17]. In general, in the experimental settings for determining the $\mathrm{T} 1$ relaxivity of the contrast agent, solvents such as water are most often used, even though they do not mimic the relevant physiological conditions; a physiological medium of human plasma was also used. [76]. T1-weighted images of IronQ's effects were achieved by increasing the image intensity of the water and human plasma in a dose-dependent manner, as indicated in Figure 9(a). Within the range of concentrations of $50-1000 \mu \mathrm{g} / \mathrm{mL}$ (0.06 to $1.23 \mathrm{mM}$ Fe by ICP-OES), this complex revealed strong spin-lattice interactions that corresponded to the higher values of the longitudinal relaxivity rate $(1 / \mathrm{T} 1)$ and the image contrast of the plasma when compared to the water phantom. In addition, the T1 relaxation rate and the cross-relaxation rate were found to be constant between the water, while the plasma proteins were correlated with an increasing percentage of protein contents [76]. The property of IronQ as a positive contrast agent in magnetic resonance imaging was determined from the $\mathrm{T} 1$ relaxivity ( $r 1)$ value that was obtained from the slope of linear fitting as a series of experimental data contrasting between the relaxation rate and the concentration of IronQ, as shown in Figure 9(b) [65]. The longitudinal relaxivity of IronQ was $2.29 \mathrm{mM}^{-1} \mathrm{~s}^{-1}$ for water and $3.70 \mathrm{mM}^{-1} \mathrm{~s}^{-1}$ for the human plasma obtained at $25^{\circ} \mathrm{C}$ under a magnetic field of 1.5 T. As mentioned above, the $\mathrm{T} 1$ relaxivity of IronQ in 

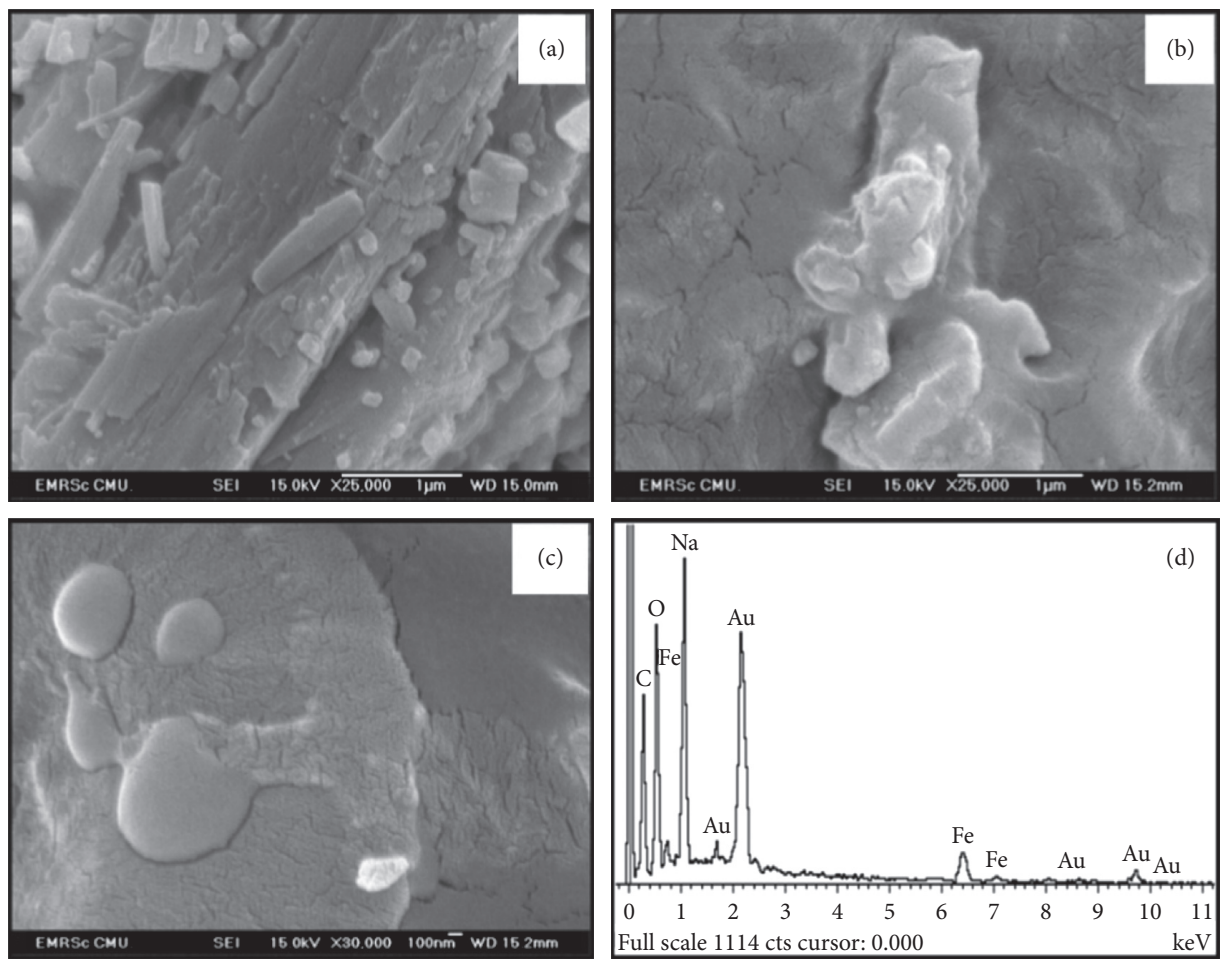

FIGURE 6: SEM images for the analysis of (a) quercetin and (b-c) IronQ at (b) 25000X and (c) 30000X amplifications followed by (d) the EDX spectrum.

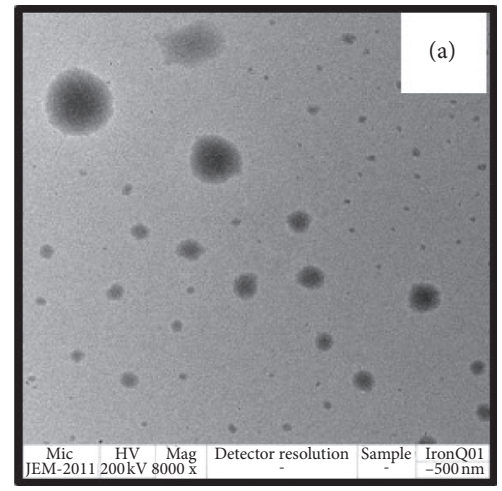

Size distribution by intensity

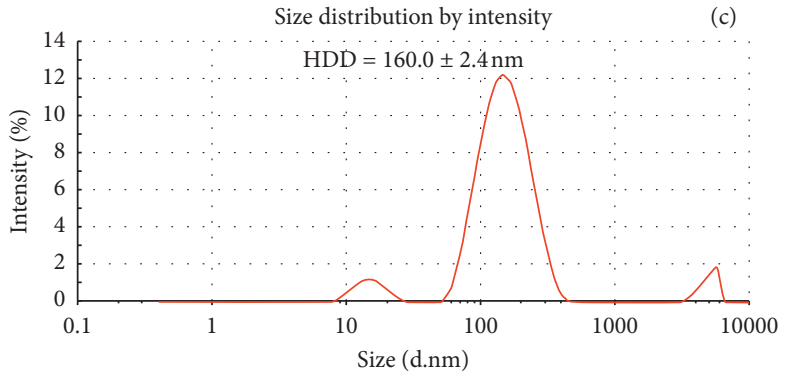

- Record 422: 07-IQ750 2
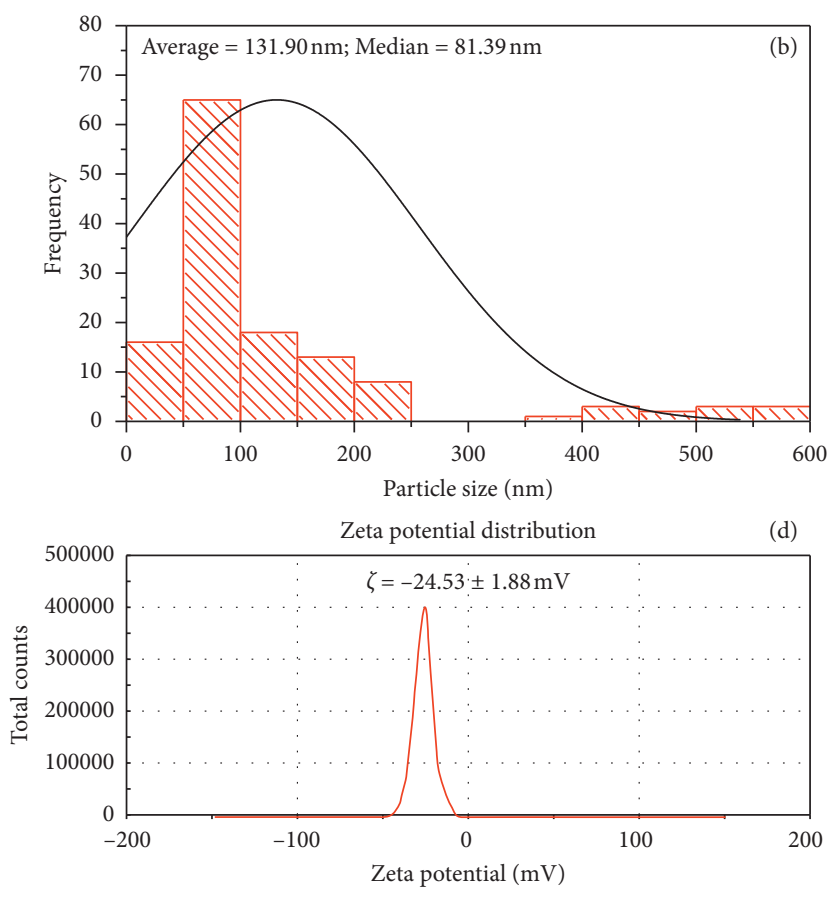

- Record 425: 07-IQ750 2

FIGURE 7: Size and zeta potential of IronQ. (a) TEM image, (b) TEM size distribution $(n=132)$, (c) hydrodynamic size ( $n=3$ ), and (d) zeta potential of IronQ $(n=3)$.

plasma exhibited a higher value than that in the water phantom. However, we observed the opposite phenomena for ferric ions $\left(\mathrm{Fe}^{3+}\right)$ through the iron (III)-water complex, which revealed a higher degree of longitudinal relaxivity in water than in plasma $\left(\mathrm{r} 1\right.$; water/plasma $\left.=3.70 / 0.28 \mathrm{mM}^{-1} \mathrm{~s}^{-1}\right)$. In addition, the iron (III)-water complex exhibited a stronger T2 effect in 


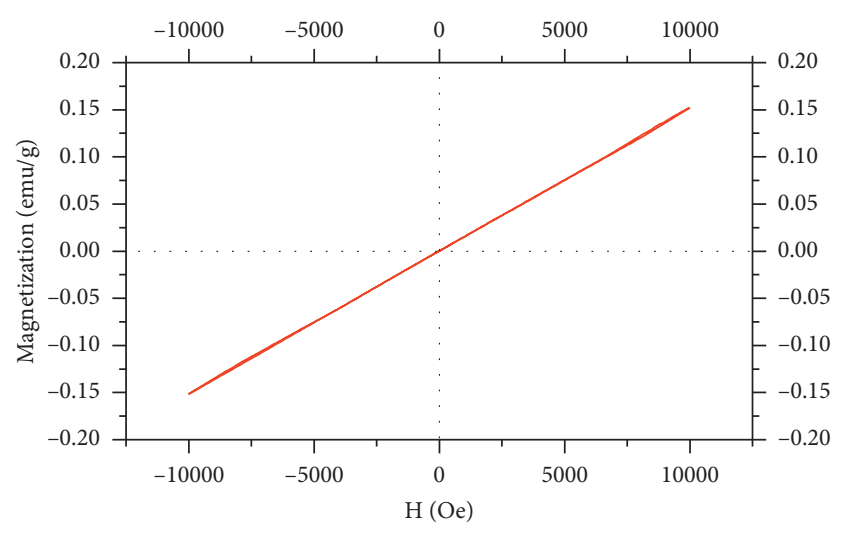

Figure 8: M-H curve of IronQ.

water than in plasma ( 2 ; water/plasma $=17.96$ ) $0.42 \mathrm{mM}^{-1} \mathrm{~s}^{-1}$ ). A reduction in the $\mathrm{r} 1$ value of the iron (III)water complex in plasma might occur as a result of two specific factors: (1) the water-protein ligand exchanges known as ligand effects and (2) the reduction of iron (III) under a high spin to iron (II) oxidation state, identified as a low spin by plasma proteins. Three mechanisms are considered to contribute to the relaxivity of IronQ: (1) innersphere relaxation through iron (III)-coordinated water molecule exchanges with other water molecules, (2) second-sphere relaxation where hydrogen bound water molecules are present in the second coordination sphere or an exchangeable hydrogen atom (such as $\mathrm{O}-\mathrm{H}$ and $\mathrm{N}-\mathrm{H}$ ) between water and plasma proteins that undergoes relaxation and exchange, and (3) outer-sphere relaxation, where water molecules can be diffused close to the IronQ and can also be relaxed $[17,64]$. The T2 relaxivity of IronQ was not evaluated in terms of its value because this complex was not involved with the spin-spin relaxation process. The $r 2 / r 1$ ratio value was close to zero. This indicates that IronQ acts as a potent $\mathrm{T} 1$ contrast agent. In general, $\mathrm{T} 1$ contrast agents have a lower $r 2 / r 1$ ratio $(r 2 / r 1<2)$, while T2 contrast agents have a larger $r 2 / r 1$ ratio (>10) [75]. Through comparison of the relaxivity of IronQ with other iron (III) complexes derived by various kinds of small molecule chelators, IronQ displayed $r 1$ values that were higher than those of Fe-DTPA $\left(r 1\right.$; water/serum $=0.6 / 0.9 \mathrm{mM}^{-1} \mathrm{~s}^{-1}$ at $\left.0.94 \mathrm{~T}\right), \mathrm{Fe}$-tCDTA $\left(\mathrm{r} 1\right.$; water/serum $=2.0 / 2.2 \mathrm{mM}^{-1} \mathrm{~s}^{-1}$ at $\left.0.94 \mathrm{~T}\right)$, and $\mathrm{Fe}-$ HBED ( $r 1$; water $=0.49 \mathrm{mM}^{-1} \mathrm{~s}^{-1}$ at $\left.1.5 \mathrm{~T}\right)$ but lower $r 1$ values than $\mathrm{Fe}_{3} 3 \mathrm{FCAT}_{3}\left(r 1\right.$; water $=3.2-7.3 \mathrm{mM}^{-1} \mathrm{~s}^{-1}$ at 4.7 T) [15-17]. Moreover, the same $r 1$ values were recorded for ligands such as quercetin, which were different for metal $\left(\mathrm{Gd}^{3+}\right)$. This difference occurs because IronQ is associated with greater $r 1$ values than those of the Gd (III)-quercetin complex [72]. Surprisingly, our results showed that the T1 relaxivity value of IronQ was within the T1 relaxivity range of the clinical T1-positive contrast agents, including Gd-DOTA, Ga-HPDO3A, Gd-DO3A-butrol, Gd-DTPA, Gd-DTPA-MBA, Gd-DTPA-BMEA, Gd-BOPTA, and Mn-DPDP, both in water (range of $1.5-4.2 \mathrm{mM}^{-1} \mathrm{~s}^{-1}$ ) and in plasma (range of $3.4-6.6 \mathrm{mM}^{-1} \mathrm{~s}^{-1}$ ), which were measured at $37^{\circ} \mathrm{C}$ and $1.5 \mathrm{~T}$ [77].
3.6. Proliferation and Morphological Observations of the PBMC-Treated Iron (III)-Quercetin Complex. Human peripheral blood mononuclear cells (PBMCs) were cultured in an RPMI 1640 medium with 10\% FBS and 1\% penicillin/ streptomycin without adding any specific growth factors, either in the absence (control) or presence of $125 \mu \mathrm{g} / \mathrm{mL}$ of the iron (III)-quercetin complex (IronQ). The adherent peripheral blood mononucleated cell population appeared under both conditions with different characteristic features. Under IronQ conditions, the cells appeared as long spindleshaped cells that were of considerable length $(\sim 100 \mu \mathrm{m})$, while the majority of cells in the control media appeared shorter in comparison (Figure 10(a)). Morphological observations at different time points revealed that, under IronQ conditions and after continuous culturing for 7-10 days, the cells became confluent and formed colonies. They then displayed a central cluster of rounded and flat cells with a radial arrangement of spindle-shaped cells (Figure 10(b)). These colonies are referred to as the colony-forming unitHill (CFU-Hill), as described previously by Hill et al., and were consistent with the endothelial progenitor cell (EPC) phenotype [78]. On day 14, adherent cells appeared homogenously as long spindle cells (Figure 10(b)). In contrast, most cells in the control culture appeared as adherent cells with several shapes and were shorter in comparison. It was revealed that IronQ promoted a greater number of adherent cells with almost $90 \%$ confluence on day 14. Furthermore, the IronQ complex treated with PBMCs resulted in an almost 3 -fold higher number of cells than that in the untreated controls at the end of the culture period. The quantification of cell proliferation over the 10 days of culturing revealed that the cells generated under IronQ conditions experienced greater proliferation (Figure 10(c)). It is well established that the cells of PBMC consist of terminally differentiated cells, including monocytes and lymphocytes. Along with mature cells, PBMC also contained a very low subset $(0.01 \%)$ of circulating endothelial progenitor cells [79]. Because monocytes and lymphocytes do not divide without the activated cytokines, under normal culture conditions, the cells will die over time [80]. Surprisingly, culturing PBMCs under IronQ composed of iron (III) and quercetin promoted the proliferation and differentiation of circulating proangiogenic cells (CACs). It has been reported in many studies that quercetin, a natural flavonoid, plays a crucial role in improving endothelial dysfunction [81, 82]. Similar to our findings, a recent study reported that a quercetin-rich-derived onion extract improves endothelial dysfunction and the EPC number in healthy overweight and obese persons [83].

The expanded spindle-shaped cells were further characterized by immunofluorescence staining for the cell surface markers of the stem/progenitor, endothelial cells, and monocytes/macrophages. Immunofluorescent staining showed that the expanded spindle-shaped cells were positive for CD14, CD31, CD45, CD105, CD133, and VEGFR2 and negative for CD34 (Figure 11). These findings were consistent with the reported characterizations of early EPCs and circulating angiogenic cells [84]. Conversely, a recent study showed that normal PBMCs were negatively 


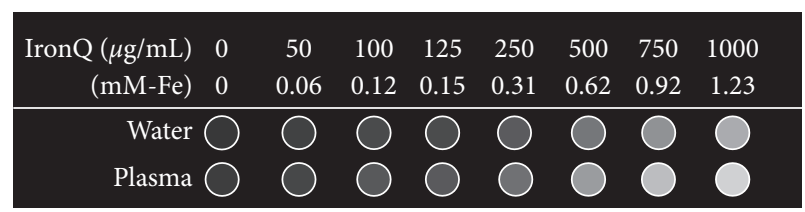

(a)

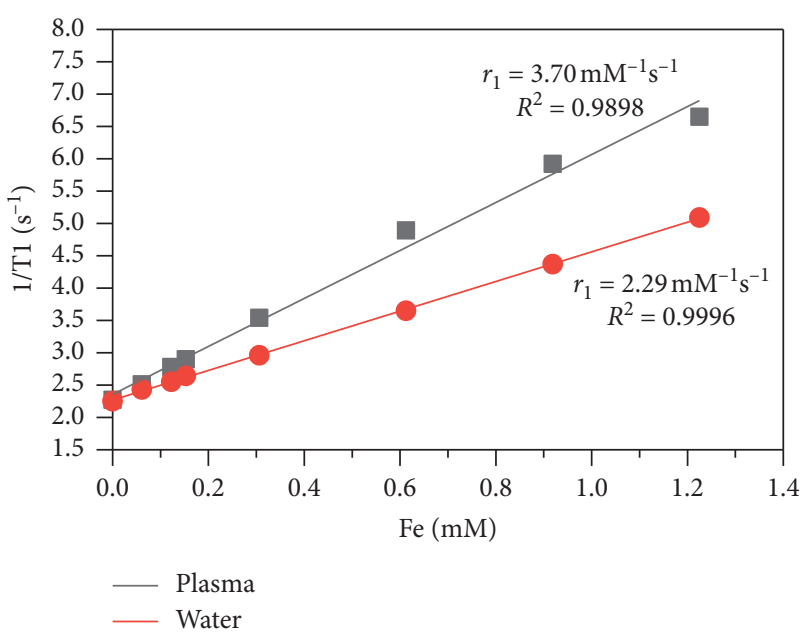

(b)

FIGURE 9: Magnetic resonance imaging properties of IronQ in water and plasma phantoms. (a) T1-weighted image showing different contrasts with increasing concentrations of IronQ $(0-1000 \mu \mathrm{g} / \mathrm{mL})$ and $(\mathrm{b})$ a plot of the relaxation rate $1 / \mathrm{T} 1$ versus the IronQ concentration.
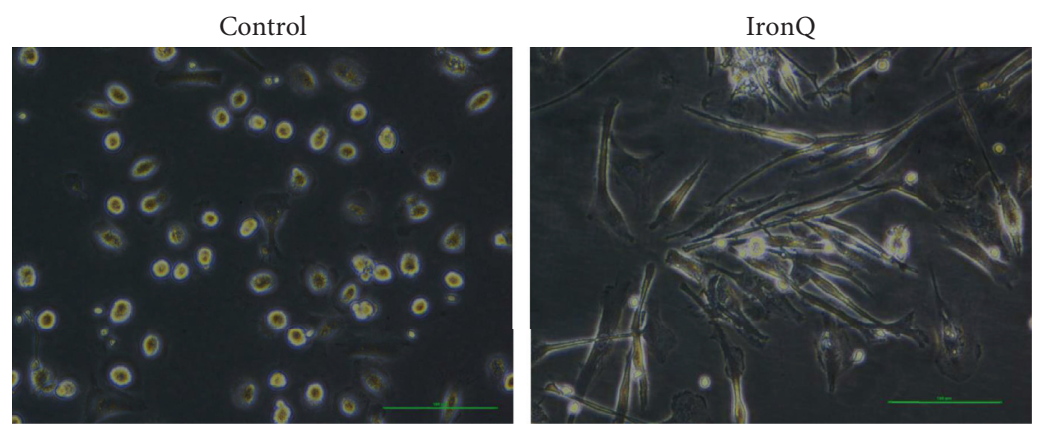

(a)

IronQ treated

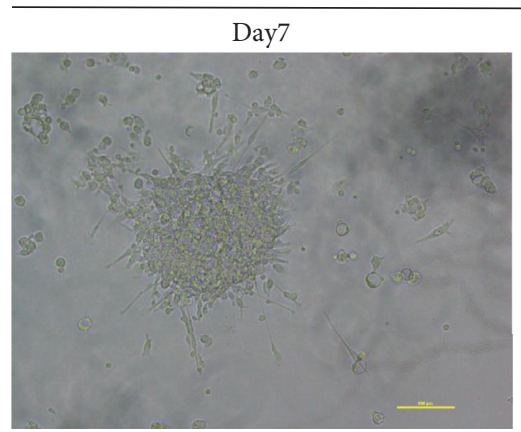

Day10

Day14
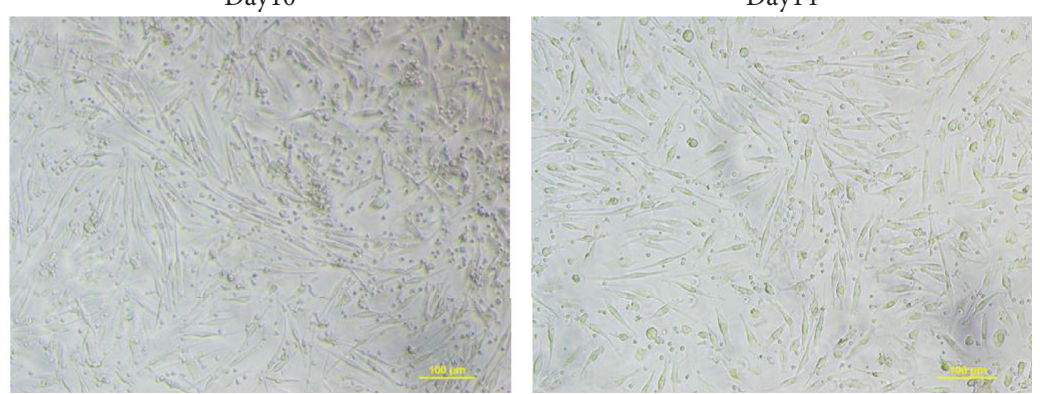

(b)

FIgURE 10: Continued. 


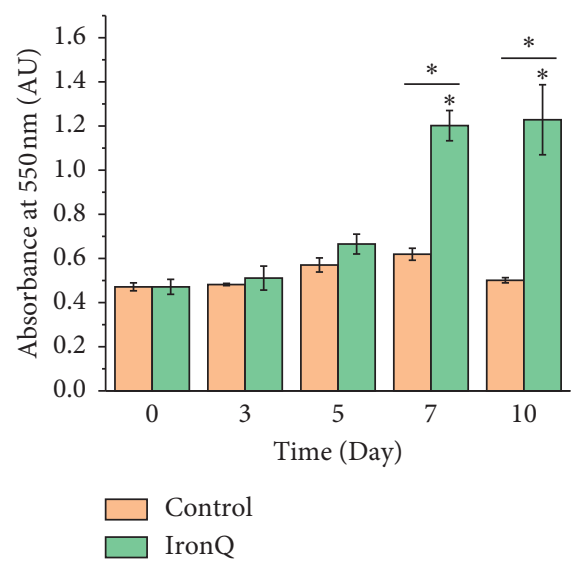

(c)

FIGURE 10: Proliferation and morphological observations on the peripheral blood mononuclear cells- (PBMCs-) treated IronQ complex. (a) Representative phase-contrast images of the morphological states of PBMCs on day 14 of the culturing process. (b) PBMCs were cultured in a culture medium without and with $125 \mu \mathrm{g} / \mathrm{mL}$ of the IronQ complex. CFU-Hill or early outgrowth EPCs were observed after 7 days of culturing, while the circulation of angiogenic cell (CAC) progeny was observed after 14 days of culturing under IronQ conditions. Scale $\mathrm{bar}=100 \mu \mathrm{m}$. (c) A proliferation assay over 10 days of culturing revealed that the cells generated under IronQ conditions showed greater proliferation $\left(n=3 ;{ }^{*} p<0.05\right)$.
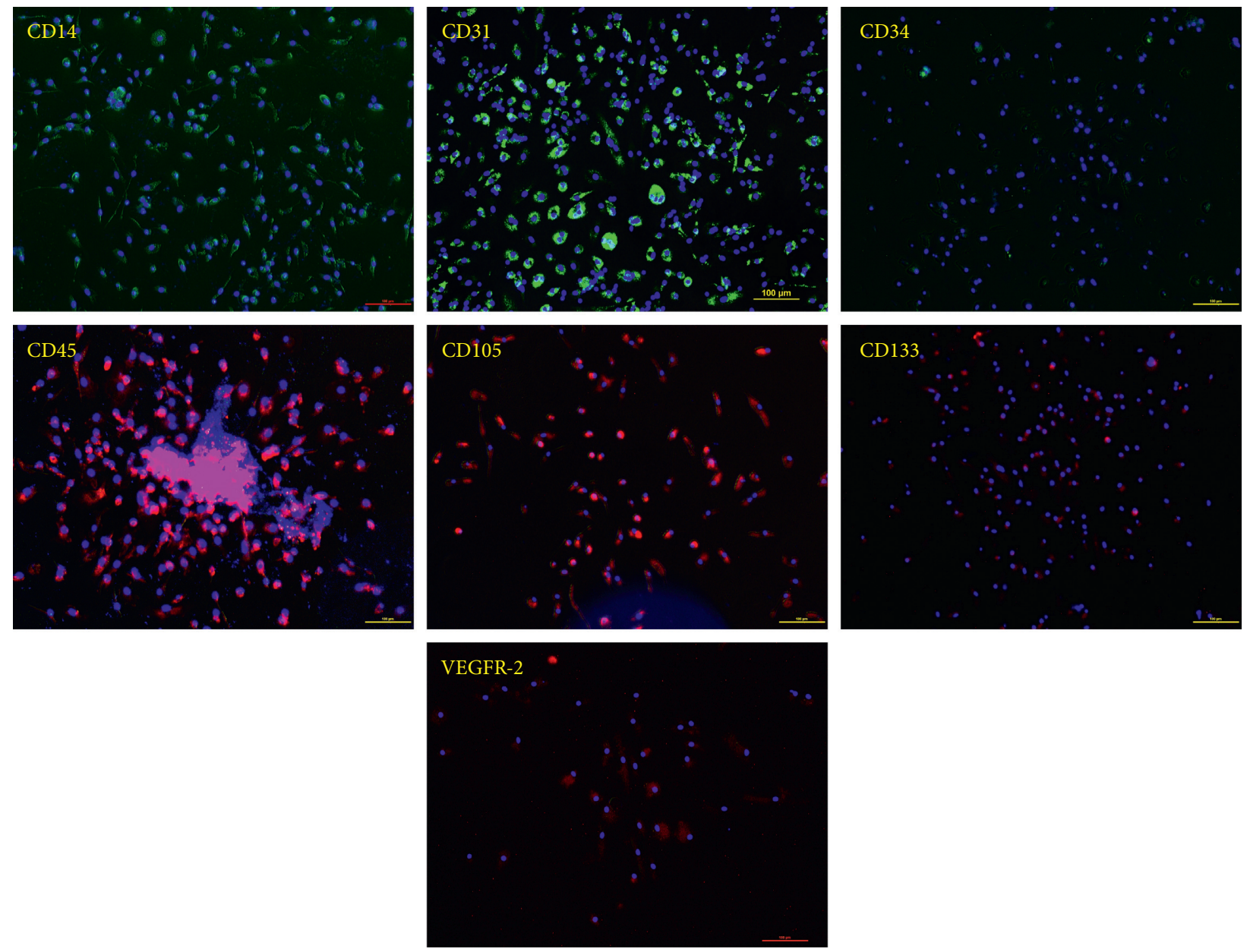

FIGURE 11: Immunofluorescence staining of IronQ-induced CACs. CACs were stained positively for monocyte and endothelial progenitor cell markers, CD14, CD31, CD45, CD105, CD133, and VEGFR-2 and negatively stained for CD34. Scale bar $=100 \mu \mathrm{m}$. 
stained for EPC markers, including CD14, CD105, VEGFR2 , and CD133, but with a strongly positive expression for the pan leukocyte marker, CD45 [85]. Originally, EPCs were recognized as hematopoietic cells unable to directly form tube-like structures. In contrast, EPCs were able to increase angiogenesis in a paracrine manner and played a role in promoting and modulating angiogenesis [86-88]. In this study, we describe a novel method for generating spindle-shaped fibroblast-like cells from nonmobilized PBMCs using a simplified culture method without any cytokine cocktail additive. Using our home-synthesized MR contrast agent "Iron (III)-quercetin complex," PBMCs cultured with the IronQ complex displayed a degree of differentiation of cells into spindle-shaped cells with fibroblastic characteristics and enhanced proliferation of blood progenitor cells. Several studies have reported on the differentiation of peripheral mononuclear cells into fibroblast-like cells, which are termed fibrocytes and endothelial progenitor cells (EPCs) or circulating angiogenic cells (CACs) and pericytes, both of which are known to play roles in proangiogenic interactions in both in vitro and in vivo experiments [89-93]. The results indicate that the cultivation of PBMCs from peripheral blood under the iron (III)-quercetin complex gives rise to proangiogenic progenitor cells. These progenitors, which we identified as circulating proangiogenic cells (CACs), are attractive as an alternative to bone-marrow-derived mesenchymal stem cells or progenitor cells for revascularising tissue after trauma and/or chronic damage. There is mounting evidence for the promising therapeutic properties of transplanted bone marrow-derived or peripheral blood-derived EPCs in the revascularization of ischemic tissue in both experimental and clinical studies [94-96]. To simplify the culture method for expanded EPCs from the PBMC population, we describe here a modified culture method to generate CACs with ease. The ease by which the sources of cells can be noninvasively obtained can reduce the cost of cell preparation. Moreover, by using IronQ to generate CACs for application in cell transplantation, we can reduce the cell tracking step because magnetic resonance imaging can track IronQ.

\subsection{Proangiogenic Potential of CACs to Promote Tube-like} Formation In Vitro. Next, we investigated whether CACs can exert their roles in proangiogenic properties by coculturing them with HUVECs in a semisolid medium Matrigel $^{\mathrm{TM}}$ assay. HUVECs were seeded in a growth medium as the control group (Figure 12(a)). Interestingly, within the cocultured system in the presence of CACs, HUVECs increased both the stability of the capillary-like tubes in the semisolid medium and their organizational efficiency. Furthermore, CACs and their conditioned medium induced a pronounced increase in their ability to promote the amount of elongation and tubular networks compared to the control situation (Figure 12(a)). The quantification analysis of the HUVEC tube length and tube number (Figures 12(b) and 12(c)) indicated that CACs and their condition medium significantly increased HUVEC tubulogenesis by approximately two-fold $(p<0.05)$. This characteristic feature was primarily attributable to enhanced angiogenic capacity from the production of angiogenic factors by culturing PBMCs under IronQ complex conditions. Similarly, blood-derived angiogenic cells were previously found to be able to increase and stabilize endothelial tubular structures following direct coculturing with HUVECs, indicating a proangiogenic effect of bloodderived angiogenic cells [91, 92]. A number of studies have also reported the proangiogenic effect of mesenchymal stem cells (MSCs), wherein MSCs derived from human bone marrow cells had the ability to regulate new blood vessel formation, stability, and function [93, 97, 98]. In summary, the data suggest a proangiogenic effect of the expanded circulating proangiogenic cells that were collected from the cultivation of peripheral blood mononuclear cells under the conditions of the MR contrast agent, the iron (III)-quercetin complex.

3.8. Intracellular Iron Uptake by Prussian Blue Assay and ICPOES Analysis. An investigation of IronQ inside the cells as a key factor in the uptake rate and internalization dynamics could provide a better understanding of how the intracellular accumulation of this complex can lead to broader applications in imaging probes for MRI, cell labeling, and tracking for stem cell biology and therapy. The accumulation of IronQ in PBMCs was monitored by a Prussian blue assay based on the reaction between the ferric ions and potassium ferrocyanide to produce the formation of blue particles that could be observed under a microscope. We observed that most of the labeled cells under a long exposure time (10 days with $125 \mu \mathrm{g} / \mathrm{mL}$ ) were positively stained with a blue color in the cytoplasm of the cells, as indicated in Figure 13(b), and clearly differed from the nonlabeled cells (Figure 13(a)). The brown color of the pelleted cells is depicted in the inset of Figure 13(b), while the nonlabeled cells displayed a paleyellow color (inset of Figure 13(a)). The amount of IronQ accumulated in the cells was measured by ICP-OES techniques, and the results are shown in Figure 13(c). The accumulation of the IronQ in PBMCs was evident in a doseand time-dependent manner $[9,99]$. PBMCs were exposed to IronQ at concentrations ranging from 0 to $200 \mu \mathrm{g} / \mathrm{mL}$ for a period of 10 days, while the iron content was significantly higher than that of the cells for a shorter period of time involving 1 day of exposure to this complex. We found that the iron contents on day 10 were around 13- to 15 -fold higher than those on day 1 , which was determined by concentrations of 25 to $100 \mu \mathrm{g} / \mathrm{mL}$. The highest degree of iron uptake was found at $63.29 \pm 6.03 \mathrm{pg}$ Fe per cell in PBMC treated with $100 \mu \mathrm{g} / \mathrm{mL}$ of IronQ for 10 days. For iron content, labeling of the endothelial progenitor cells (EPCs) derived from the PBMCs via SPIO at $20 \mu \mathrm{g} / \mathrm{mL}$ for $24 \mathrm{~h}$ detected values of $13.6 \pm 1.8 \mathrm{pg}$ Fe per cell [100], which were higher than the values determined by labeling the PBMCs via the T1-contrast agent IronQ $(1.65 \pm 0.11 \mathrm{pg}$ Fe per cell $)$ at $25 \mu \mathrm{g} / \mathrm{mL}$ for $24 \mathrm{~h}$. However, at the same time of incubation at a higher concentration $(200 \mu \mathrm{g} / \mathrm{mL})$, the PBMCs utilized IronQ at up to $12.31 \pm 2.10 \mathrm{pg}$ Fe per cell. In addition, the 

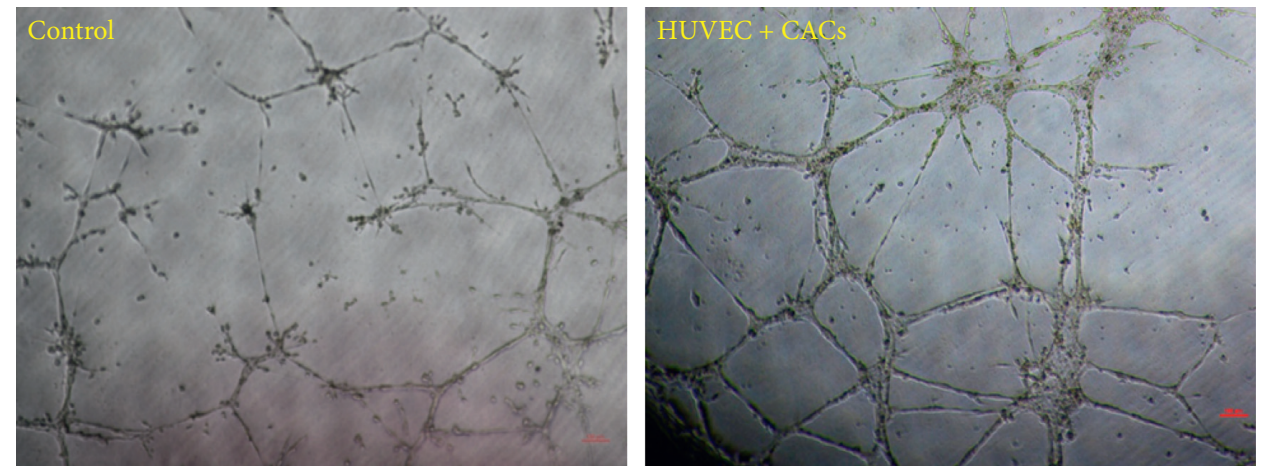

(a)

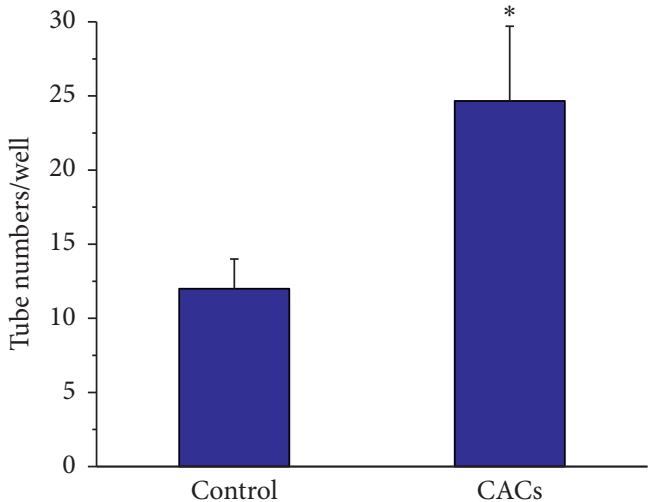

(b)

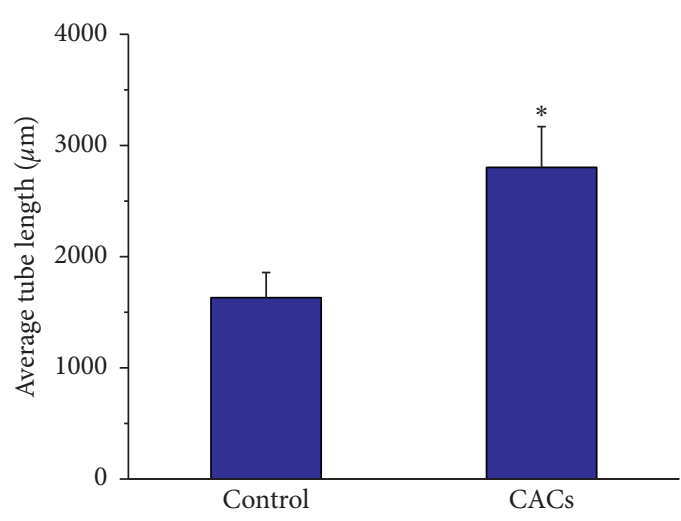

(c)

FIgURE 12: IronQ-induced CACs promoted tube-like formations during coculturing with HUVECs. (a) Representative endothelial tube formation following $24 \mathrm{~h}$ of incubation with CACs and their conditioned medium in Matrigel ${ }^{\circledR}$. Control: HUVEC in the growth medium, HUVEC + CACs: HUVEC coculture with CACs and the condition medium of CACs. Scale bars $=100 \mu \mathrm{m}$. (b), (c) Graph showing the average endothelial tube number and tube length $(\mu \mathrm{m})$. Notably, this assay was performed 8 independent times on matched samples from 8 different donors $\left({ }^{*} p<0.05\right)$.

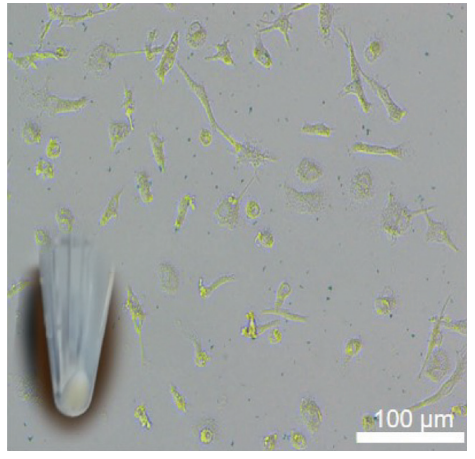

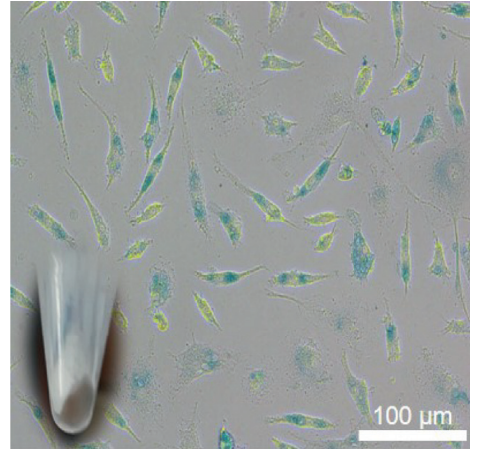

(b)

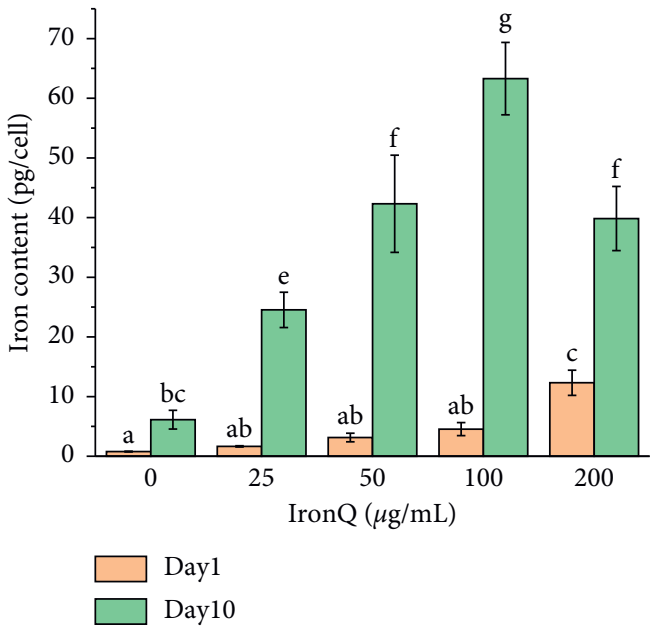

(c)

FIgURE 13: Intracellular iron contents: (a) Prussian blue staining of iron in the nonlabeled PBMCs (control) and (b) $125 \mu \mathrm{g} / \mathrm{mL}$ labeled IronQ. (c) Quantitative analysis of intracellular iron contents of PBMC labeled with 25, 50, 100, and $200 \mu \mathrm{g} / \mathrm{mL}$ of IronQ using ICP-OES analysis for day 1 and day 10. Different lowercase letters indicate significant difference according to the ANOVA analysis followed by Tukey's test $(n=3 ; p<0.05)$. 
highly efficient labeling of human mesenchymal stem cells with $25 \mu \mathrm{g} / \mathrm{mL}$ of Citrated SPIONs for $24 \mathrm{~h}$ without the use of a transfection agent was reported at $69.6 \pm 5.1 \mathrm{pg}$ Fe per cell, while a higher degree of efficiency than that for Endorem SPIONs $(25.7 \pm 6.5 \mathrm{pg}$ Fe per cell) was observed under the same conditions [9]. However, the iron content decreased from the highest value when the concentration of the IronQ was higher than $100 \mu \mathrm{g} / \mathrm{mL}$. These contradictory results could be due to the proliferation effect of IronQ. This result confirmed that proliferation occurred in the PBMCtreated IronQ. Thus, as the cells proliferated, the amount of IronQ in each cell decreased, and IronQ uptake could not be detected in some cells [101]. Another reason might be that the maximum iron content achieved for the activities of PBMCs induced by IronQ was $\sim 70 \mathrm{pg}$ Fe per cell, while the iron overload might have been removed via exocytosis. However, a further study should be conducted to confirm this outcome. Indeed, cell labeling efficiency is dependent upon many factors, including the type of cells (e.g., human endothelial progenitor cells, human mesenchymal stem cells, human embryonic stem cells, human adult neural stem cells, or PBMCs) and cell origin (human or murine); the physicochemical properties (e.g., size, charge, and formulation) of the imaging probes; the concentration values of the probes that had no effect on the viability, differentiation, and function of the labeled cells; and the conditions associated with labeling (e.g., incubation time, cell density, and with or without the aid of transfection techniques) [4, 6, 9, 102-107]. Most of the magnetic resonance imaging probes used to label the stem cells in both clinical and preclinical procedures were based on superparamagnetic iron oxide nanoparticles (SPIONs) that provided negative $\mathrm{T} 2$ - or $\mathrm{T} 2{ }^{*}$-weighted images, such as dextran-coated iron oxide (Endorem/Feridex ${ }^{\circledR}$; the U.S. Food and Drug Administration (FDA) approved it, but the product has been discontinued), carboxymethyl dextrancoated ferucarbotran (Resovist ${ }^{\circledR}$, which was FDA approved but discontinued), ferumoxytol/Feraheme (an FDAapproved product for iron deficiency treatment in anemia), and Molday ION EverGreen, FeraTrack, and Dargon Green-encapsulated magnetic polymers. These agents under development have been reported to be capable of achieving biocompatible intracellular stem cell labeling, along with the uptake of 2-9 pg Fe per cell [6]. More recently, the labeling of MSCs involved in cellular uptake was proven for more than $10 \mathrm{pg} F e$ per cell without the use of transfection agents, as reported for very small iron oxide (VSOP; 21 pg Fe per cell) and multicore carboxymethyl dextran-coated iron oxide nanoparticles (multicore particles, MCP; $17 \mathrm{pg}$ Fe per cell) with $2 \mathrm{mM}$ of the imaging probes for $24 \mathrm{~h}$ [6]. A higher degree of uptake of the imaging probes by cells could improve the MR imaging signal for hematopoietic progenitor/stem cell tracking in both preclinical and clinical therapies $[4,103,104,107]$.

3.9. In Vitro Evaluation of Cell Labeling by MRI. As mentioned above, the PBMCs labeled with IronQ were brown colored, and the color gradually changed to dark brown
(Figure 14(a)), which corresponded with an increasing concentration of the complex accumulated within the cells (Figure 14(c)). Similar results were observed after the in vitro MRI experiments of PBMCs, wherein IronQ enhanced the brightness intensity of $\mathrm{T} 1$-weighted images as an indication of the concentration amount $(0,25,50,100$, and $200 \mu \mathrm{g} / \mathrm{mL})$ and the incubation time (1 day and 10 days), as shown in Figures 14(b) and 14(c). The highest concentration used in this study, $200 \mu \mathrm{g} / \mathrm{mL}$, revealed no differences between the maximum $\mathrm{T} 1$ signal intensities at day 10 and day 1 of the incubation period (Figure 14(c)). There are many possibilities for this result: (1) During the culture period of PBMCs with IronQ, the useful cells of IronQ in proliferation and differentiation processes and the interactions between IronQ and biomolecules or metabolites in the cells may have resulted in the conformation and/or oxidation state of IronQ changes. These may include IronQ metabolite products, the self-aggregation of IronQ, and the highspin Iron (III)-quercetin complex changing to a low-spin Iron (II)-quercetin complex involved in reducing $\mathrm{T} 1$ relaxivity [108]. Thus, a stability test and pharmacokinetics study of IronQ are necessary to achieve the next goal of improving labeling efficiency and MRI tracking. (2) An unsuitably long repetition time ( $\mathrm{TR}=525 \mathrm{~ms}$ ) was used, which did not allow discrimination of the $\mathrm{T} 1$ signal intensity under this spin-echo pulse sequence [109]. This result suggests that the appropriate conditions for the labeling of PBMCs and imaging via T1-weighted MRI included $5 \times 10^{6}$ cells, a concentration of IronQ at $200 \mu \mathrm{g} / \mathrm{mL}$, and $24 \mathrm{~h}$ of incubation time at $37^{\circ} \mathrm{C}$ in a humidified incubator. Moreover, by using the spin-echo pulse sequence, the suitable TR value was less than $525 \mathrm{~ms}$ for the IronQlabeled cell tracking under MRI. However, experimental settings that include a pulse sequence for optimizing IronQ-labeled cell tracking both in vitro and in vivo are necessary considerations. Indeed, we could label the PBMCs with a higher concentration of IronQ, such as $500 \mu \mathrm{g} / \mathrm{mL}$, and culture the IronQ labeled cells for a longer period of time at 14 and 21 days, to expand the progeny's angiogenic cells for therapeutic purposes [38]. An ideal cell tracer agent must also show effective cellular labeling and low cytotoxicity. Although SPION-based T2/T2* contrast agents have advantages, including high degrees of sensitivity and biocompatibility, there are numerous potential applications for stem cell labeling and tracking by MRI in both preclinical and clinical settings. However, the superparamagnetic iron oxide nanoparticles provided dark signals that might be the result of obliteration in the surrounding anatomy and could be nonspecific concerning the source of the dark signal, which could be indicative of microbleeds, haemorrhages, the air/tissue interface, or released SPIONs internalized by macrophages [104]. To avoid this interference, an alternative bright-contrast cell tracking process using paramagnetic T1 contrast agents was applied in preclinical settings. Examples of T1 contrast agents identified as Gd-DTPA (Magnevist, FDA approved) and gadodiamide (Omniscan, FDA approved), as well as manganese porphyrin-based contrast agents, such as MnAMP, $\mathrm{MnPNH}_{2}$, and MnEtP, were applied in 

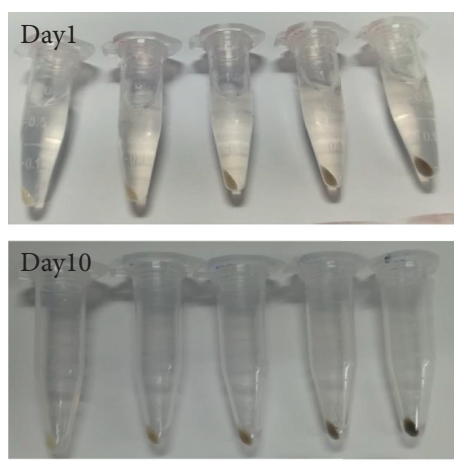

\begin{tabular}{llll}
0 & $25 \quad 50$ & 100 & 200 \\
\hline
\end{tabular}

(a)

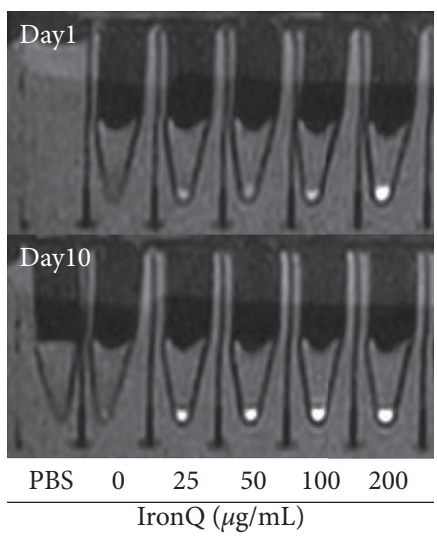

(b)

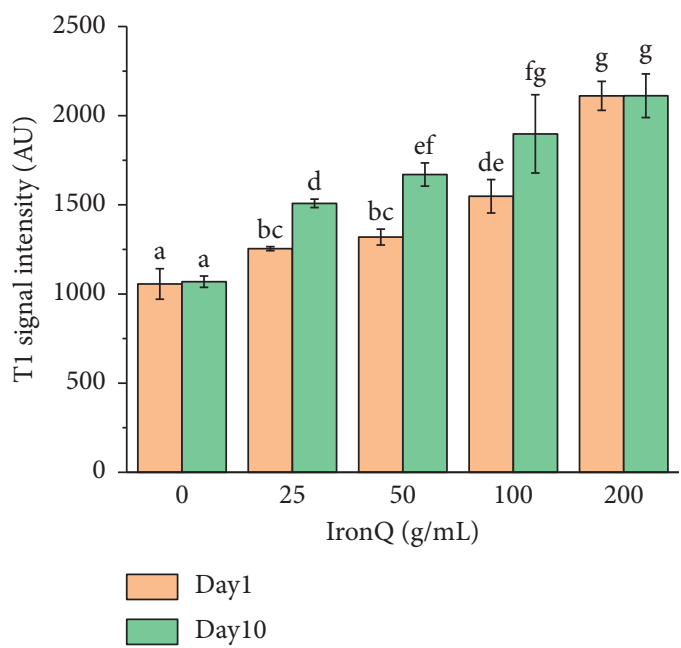

(c)

Figure 14: In vitro MRI studies: (a) physical observations, (b) T1-weighted images from a sagittal view, and (c) a plot of the T1 signal intensity of PBMC pellets labeled with IronQ at various concentrations in microcentrifuge tubes with phosphate buffer saline (PBS) on day 1 and day 10 of the incubation period. Different lowercase letters indicate significant difference according to the ANOVA analysis followed by Tukey's test $(n=3 ; p<0.05)$.

preclinical settings $[104,110-112]$. Amongst T1 cell-labeling agents, there have been a plethora of approaches based on both gadolinium (Gd) and manganese. Clinically approved Gd chelating contrast agents are small, hydrophilic, and have cell-impermeable properties. In contrast, manganese porphyrins are naturally hydrophobic due to their larger aromatic macrocycles. Regarding their properties, these agents require high concentrations with or without transfection agents and use a long labeling time for cell uptake [113]. Here, we provided a new smart candidate T1 contrast agent, IronQ, for stem cell labeling. The preparation of IronQ involves a simple one-step synthesis from commercially available quercetin and iron (III) chloride. IronQ is a water-soluble agent and biologically safe. In the labeling process, IronQ are loaded up to $70 \mathrm{pg}$ Fe per cell with a short incubation time of $24 \mathrm{~h}$, and transfection agents are not required. In comparison to other paramagnetic $\mathrm{T} 1$ contrast agents, the main advantage of our novel smart candidate T1 contrast agent, IronQ, is its biological safety, as the main components are endogenous substances found in the human body and easily eliminated through physiological functions. Moreover, IronQ has almost no cytotoxicity in PBMCs and is suitable to use for stem cell tracking without negative effects on stem cell properties. We showed in this study that IronQ can induce the proliferation and differentiation of circulating angiogenic cells. Future studies will focus on optimizing the labeling conditions for several different types of therapeutic cells, such as hematopoietic stem cells, mesenchymal stem cells, and neural stem cells, for regenerative medicine. These analyses will be followed by in vivo studies to optimize the injection protocols for therapeutic cells in preclinical animal models of stem cell therapy. In the present study, we proposed IronQ as a positive T1 contrast agent with high potential for labeling the proangiogenic cells derived from human peripheral blood mononuclear cells and for tracking through MRI applications.

\section{Conclusions}

In the present study, we succeeded in synthesizing the iron (III)-quercetin complex IronQ with a stoichiometry ratio of $1: 2$ iron (III) and quercetin. The black powder IronQ product displayed the following physicochemical characteristics: a solid median size of $81 \mathrm{~nm}$, a hydrodynamic diameter of $160.0 \pm 2.4 \mathrm{~nm}$ in water, solubility in water, and a negative charge on the surface with a zeta potential of $-24.53 \pm 1.88 \mathrm{mV}$, showing paramagnetic behavior with a saturation magnetization of $0.155 \mathrm{emu} / \mathrm{g}$ at $1.0 \mathrm{~T}$ along with characteristic electronic light absorption peaks at wavelengths of $290 \mathrm{~nm}$ and $450-700 \mathrm{~nm}$. We found that IronQ at $125 \mu \mathrm{g} / \mathrm{mL}$ was safe and could be used in the long-term culturing (21 days) of PBMCs. Surprisingly, IronQ promoted the circulation of proangiogenic cell (CAC) growth in the conventional cell culture system without the addition of specific growth factors. IronQ can be uptaken into CACs depending on the dose and labeling time due to the advantages of the paramagnetic properties of IronQ, which allowed us to monitor the IronQ-labeled cells via MRI with the T1-weighted technique. IronQ displays paramagnetic T1-positive contrast agent properties accompanied by a longitudinal relaxivity of $2.29 \mathrm{mM}^{-1} \mathrm{~s}^{-1}$ for water and $3.70 \mathrm{mM}^{-1} \mathrm{~s}^{-1}$ for human plasma obtained at $25^{\circ} \mathrm{C}$ under a magnetic field of $1.5 \mathrm{~T}$. The findings of this study clearly indicate that IronQ can enhance the T1 signal intensity on T1-weighted images in both water and plasma phantoms, as well as in vitro IronQ-labeled cells. Taken together, all evidence indicates that IronQ has excellent abilities as both an imaging probe for MRI and a stimulating agent favoring circulating angiogenic cell differentiation. 
Therefore, we assert that IronQ could be useful for the labeling and tracking of autologous blood-derived endothelial circulation angiogenic cells and/or other stem cells in the application of vascularization and tissue regeneration via noninvasive magnetic resonance imaging in both preclinical and clinical settings.

\section{Data Availability}

The data used to support the findings of this study are available from the corresponding author upon request.

\section{Conflicts of Interest}

The authors declare that there are no conflicts of interest regarding the publication of this paper.

\section{Authors' Contributions}

Phakorn Papan and Jiraporn Kantapan contributed equally to this work.

\section{Acknowledgments}

JK and ND extend their thanks to Chiang Mai University for providing the EMIM 2018 annual meeting fee and associated travel expenses. PP thanks the Human Resource Development in Science Project (Science Achievement Scholarship of Thailand, SAST) for financial support.

\section{Supplementary Materials}

Supplementary Materials: Figure S1: ${ }^{1} \mathrm{H}$ NMR spectra for quercetin. Figure S2: ${ }^{1} \mathrm{H}$ NMR spectra for deprotonated quercetin. Figure S3: ${ }^{1} \mathrm{H}$ NMR spectra for IronQ. (Supplementary Materials)

\section{References}

[1] M. Kabat, I. Bobkov, S. Kumar, and M. Grumet, "Trends in mesenchymal stem cell clinical trials 2004-2018: is efficacy optimal in a narrow dose range?" Stem Cells Translational Medicine, vol. 9, no. 1, pp. 17-27, 2020.

[2] V. Volarevic, B. S. Markovic, M. Gazdic et al., "Ethical and safety issues of stem cell-based therapy," International Journal of Medical Sciences, vol. 15, no. 1, pp. 36-45, 2018.

[3] C. E. P. Goldring, P. A. Duffy, N. Benvenisty et al., "Assessing the safety of stem cell therapeutics," Cell Stem Cell, vol. 8, no. 6, pp. 618-628, 2011.

[4] A. Stroh, J. Kressel, R. Coras et al., "A safe and effective magnetic labeling protocol for MRI-based tracking of human adult neural stem cells," Frontiers in Neuroscience, vol. 13, Article ID 1092, 2019.

[5] R. Yahyapour, B. Farhood, G. Graily et al., "Stem cell tracing through MR molecular imaging," Tissue Engineering and Regenerative Medicine, vol. 15, no. 3, pp. 249-261, 2018.

[6] A. A. De Schellenberger, H. Kratz, T. D. Farr et al., "Labeling of mesenchymal stem cells for MRI with single-cell sensitivity," International Journal of Nanomedicine, vol. 11, pp. 1517-1535, 2016.

[7] F. Alexis, E. Pridgen, L. K. Molnar, and O. C. Farokhzad, "Factors affecting the clearance and biodistribution of polymeric nanoparticles," Molecular Pharmaceutics, vol. 5, no. 4, pp. 505-515, 2008.

[8] W. S. Yun, S. Aryal, Y. J. Ahn, Y. J. Seo, and J. Key, "Engineered iron oxide nanoparticles to improve regenerative effects of mesenchymal stem cells," Biomedical Engineering Letters, vol. 10, no. 2, pp. 259-273, 2020.

[9] K. Andreas, R. Georgieva, M. Ladwig et al., "Highly efficient magnetic stem cell labeling with citrate-coated superparamagnetic iron oxide nanoparticles for MRI tracking," Biomaterials, vol. 33, no. 18, pp. 4515-4525, 2012.

[10] H. Wei, O. T. Bruns, M. G. Kaul et al., "Exceedingly small iron oxide nanoparticles as positive MRI contrast agents," Proceedings of the National Academy of Sciences, vol. 114, no. 9, pp. 2325-2330, 2017.

[11] X. Duan and Y. Li, "Physicochemical characteristics of nanoparticles affect circulation, biodistribution, cellular internalization, and trafficking," Small, vol. 9, pp. 1521-1532, 2013.

[12] G. Kania, M. Sternak, A. Jasztal et al., "Uptake and bioreactivity of charged chitosan-coated superparamagnetic nanoparticles as promising contrast agents for magnetic resonance imaging," Nanomedicine: Nanotechnology, Biology and Medicine, vol. 14, no. 1, pp. 131-140, 2018.

[13] Q. Feng, Y. Liu, J. Huang, K. Chen, J. Huang, and K. Xiao, "Uptake, distribution, clearance, and toxicity of iron oxide nanoparticles with different sizes and coatings," Scientific Reports, vol. 8, no. 1, Article ID 2082, 2018.

[14] S. Waldvogel-Abramowski, G. Waeber, C. Gassner et al., "Physiology of iron metabolism," Transfusion Medicine and Hemotherapy, vol. 41, no. 3, pp. 213-221, 2014.

[15] N. Kuźnik and M. Wyskocka, "Iron (III) contrast agent candidates for MRI: a survey of the structure-effect relationship in the last 15 years of studies," European Journal of Inorganic Chemistry, vol. 4, pp. 445-458, 2016.

[16] P. Boehm-Sturm, A. Haeckel, R. Hauptmann, S. Mueller, C. K. Kuhl, and E. A. Schellenberger, "Low-molecular-weight iron chelates may Be an alternative to gadolinium-based contrast agents for T1-weighted contrast-enhanced MR imaging," Radiology, vol. 286, no. 2, pp. 537-546, 2018.

[17] B. C. Bales, B. Grimmond, B. F. Johnson et al., "Fe-HBED analogs: a promising class of iron-chelate contrast agents for magnetic resonance imaging," Contrast Media \& Molecular Imaging, vol. 2019, Article ID 8356931, 10 pages, 2019.

[18] Z. Zhao, Z. Zhou, J. Bao et al., "Octapod iron oxide nanoparticles as high-performance $\mathrm{T} 2$ contrast agents for magnetic resonance imaging," Nature Communications, vol. 4, no. 1, Article ID 2266, 2013.

[19] R. Wei, T. Zhou, C. Sun et al., "Iron-oxide-based twin nanoplates with strong T2 relaxation shortening for contrast-enhanced magnetic resonance imaging," Nanoscale, vol. 10, no. 38, pp. 18398-18406, 2018.

[20] R. C. Hider and T. Zhou, "The design of orally active iron chelators," Annals of the New York Academy of Sciences, vol. 1054, no. 1, pp. 141-154, 2005.

[21] H. C. Hatcher, R. N. Singh, F. M. Torti, and S. V. Torti, "Synthetic and natural iron chelators: therapeutic potential and clinical use," Future Medicinal Chemistry, vol. 1, no. 9, pp. 1643-1670, 2009.

[22] P. Ryan and M. J. Hynes, "The kinetics and mechanisms of the reactions of iron (III) with quercetin and morin," Journal of Inorganic Biochemistry, vol. 102, no. 1, pp. 127-136, 2008.

[23] J. Zhou, L. F. Wang, J. Y. Wang, and N. Tang, "Synthesis, characterization, antioxidative and antitumor activities of 
solid quercetin rare earth (III) complexes," Journal of Inorganic Biochemistry, vol. 83, no. 1, pp. 41-48, 2001.

[24] G. M. Escandar and L. F. Sala, "Complexing behavior of rutin and quercetin," Canadian Journal of Chemistry, vol. 69, no. 12, pp. 1994-2001, 1991.

[25] W. M. B. Da Silva, S. De Oliveira Pinheiro, D. R. Alves et al., "Synthesis of quercetin-metal complexes, in vitro and in silico anticholinesterase and antioxidant evaluation, and in vivo toxicological and anxiolitic activities," Neurotoxicity Research, vol. 37, no. 4, pp. 893-903, 2020.

[26] M. M. Kasprzak, A. Erxleben, and J. Ochocki, "Properties and applications of flavonoid metal complexes," RSC Advances, vol. 5, no. 57, pp. 45853-45877, 2015.

[27] R. F. V. De Souza and W. F. De Giovani, "Antioxidant properties of complexes of flavonoids with metal ions," Redox Report, vol. 9, no. 2, pp. 97-104, 2004.

[28] M. Zahedi, R. Ghiasvand, A. Feizi, G. Asgari, and L. Darvish, "Does quercetin improve cardiovascular risk factors and inflammatory biomarkers in women with type 2 diabetes: a double-blind randomized controlled clinical trial," International Journal of Preventive Medicine, vol. 4, no. 7, pp. 777-785, 2013.

[29] A. Maalik, F. Khan, A. Mumtaz et al., "Pharmacological applications of quercetin and its derivatives: a short review," Tropical Journal of Pharmaceutical Research, vol. 13, no. 9, pp. 1561-1566, 2014.

[30] S. Dechsupa, S. Kothan, J. Vergote et al., "Quercetin, siamois 1 and siamois 2 induce apoptosis in human breast cancer MDA-MB-435 cells xenograft in vivo," Cancer Biology \& Therapy, vol. 6, no. 1, pp. 56-61, 2007.

[31] W. Wang, C. Sun, L. Mao et al., "The biological activities, chemical stability, metabolism and delivery systems of quercetin: a review," Trends in Food Science \& Technology, vol. 56, pp. 21-38, 2016.

[32] R. Álvarez-Diduk, M. T. Ramírez-Silva, and A. Galano, "Deprotonation mechanism and acidity constants in aqueous solution of flavonols: a combined experimental and theoretical study," The Journal of Physical Chemistry B, vol. 41, pp. 12347-12359, 2013.

[33] S. M. Ahmadi, G. Dehghan, M. A. Hosseinpourfeizi, J. E. N. Dolatabadi, and S. Kashanian, "Preparation, characterization, and DNA binding studies of water-soluble quercetin-molybdenum (VI) complex," DNA and Cell Biology, vol. 30, no. 7, pp. 517-523, 2011.

[34] M. Leopoldini, N. Russo, S. Chiodo, and M. Toscano, "Iron chelation by the powerful antioxidant flavonoid quercetin," Journal of Agricultural and Food Chemistry, vol. 54, no. 17, pp. 6343-6351, 2006.

[35] G. Dehghan, J. E. N. Dolatabadi, A. Jouyban, K. A. Zeynali, S. M. Ahmadi, and S. Kashanian, "Spectroscopic studies on the interaction of quercetin-terbium (III) complex with calf thymus DNA," DNA and Cell Biology, vol. 30, no. 3, pp. 195-201, 2011.

[36] J. P. Cornard and J. C. Merlin, "Spectroscopic and structural study of complexes of quercetin with Al (III)," Journal of Inorganic Biochemistry, vol. 92, no. 1, pp. 19-27, 2002.

[37] G. L. Nest, O. Caille, M. Woudstra et al., "Zn-polyphenol chelation: complexes with quercetin, $(+)$-catechin, and derivatives: II Electrochemical and EPR studies," Inorganica Chimica Acta, vol. 357, no. 7, pp. 2027-2037, 2004.

[38] J. Kantapan, S. Dejphirattanamongkhol, K. Daowtak, S. Roytrakul, P. Sangthong, and N. Dechsupa, "Ex vivo expansion of EPCs derived from human peripheral blood mononuclear cells by iron-quercetin complex," Biomedical Research, vol. 28, no. 6, pp. 2730-2737, 2017.

[39] J. Kantapan and N. Dechsupa, "Novel bifunctional MRI probe: iron-quercetin complex induced differentiation of circulating mononuclear progenitor cells and therapeutic impact in cardiovascular diseases," in Proceedings of the EMIM 2018 13th Annual Meeting, Madrid, Spain, March 2018.

[40] J. Kantapan, K. Gateprayoon, K. Daowtak, P. Sangthong, and N. Dechsupa, "Quercetin iron (III) complex enhances radiation-induced cell death in human erythroleukemic cell lines by increasing the generation of intracellular ROS," American Journal of Applied Sciences, vol. 14, no. 1, pp. 104-115, 2013.

[41] J. S. Renny, L. L. Tomasevich, E. H. Tallmadge, and D. B. Collum, "Method of continuous variations: applications of Job plots to the study of molecular associations in organometallic chemistry," Angewandte Chemie International Edition, vol. 52, no. 46, pp. 11998-12013, 2013.

[42] M. L. González, M. B. Joray, J. Laiolo et al., "Cytotoxic activity of extracts from plants of central Argentina on sensitive and multidrug-resistant leukemia cells: isolation of an active principle from Gaillardia megapotamica," Evidence-Based Complementary and Alternative Medicine, vol. 2018, Article ID 9185935, 13 pages, 2018.

[43] Y. Liu and M. Guo, "Studies on transition metal-quercetin complexes using electrospray ionization tandem mass spectrometry," Molecules, vol. 20, no. 5, pp. 8583-8594, 2015.

[44] Y.-H. Lee and P.-T. Tuyet, "Synthesis and biological evaluation of quercetin-zinc (II) complex for anti-cancer and anti-metastasis of human bladder cancer cells," In Vitro Cellular \& Developmental Biology-Animal, vol. 55, no. 6, pp. 395-404, 2019.

[45] V. T. Barbosa, J. B. De Menezes, J. C. C. Santos et al., "Characterization and stability of the antimony-quercetin complex," Advanced Pharmaceutical Bulletin, vol. 9, no. 3, pp. 432-438, 2019.

[46] S. Kaviarasi, K. S. Shalini Devi, P. Vinoth et al., "Synthesis, characterization, and biomedical applications of an alkylated quercetin-gadolinium complex," ACS Biomaterials Science \& Engineering, vol. 5, no. 3, pp. 1215-1227, 2019.

[47] V. Uivarosi and A. C. Munteanu, Flavonoid Complexes as Promising Anticancer Metallodrugs, Intech, London, UK, 2017.

[48] A. Raza, X. Xu, L. Xia, C. Xia, J. Tang, and Z. Ouyang, "Quercetin-iron complex: synthesis, characterization, antioxidant, DNA binding, DNA cleavage, and antibacterial activity studies," Journal of Fluorescence, vol. 26, no. 6, pp. 2023-2031, 2016.

[49] J. M. D. Marković, Z. S. Marković, T. P. Brdarić, V. M. Pavelkić, and M. B. Jadranin, "Iron complexes of dietary flavonoids: combined spectroscopic and mechanistic study of their free radical scavenging activity," Food Chemistry, vol. 129, no. 4, pp. 1567-1577, 2011.

[50] M. Samsonowicz and E. Regulska, "Spectroscopic study of molecular structure, antioxidant activity and biological effects of metal hydroxyflavonol complexes," Spectrochimica Acta Part A: Molecular and Biomolecular Spectroscopy, vol. 173, pp. 757-771, 2017.

[51] J. M. Herrero-Martínez, M. Sanmartin, M. Rosés, E. Bosch, and C. Ràfols, "Determination of dissociation constants of flavonoids by capillary electrophoresis," Electrophoresis, vol. 26, no. 10, pp. 1886-1895, 2005. 
[52] S. Sunoqrot, E. Al-Shalabi, and P. B. Messersmith, "Facile synthesis and surface modification of bioinspired nanoparticles from quercetin for drug delivery," Biomaterials Science, vol. 6, no. 10, pp. 2656-2666, 2018.

[53] S. Sunoqrot, E. Al-Shalabi, L. H. Ibrahim, and H. Zalloum, "Nature-inspired polymerization of quercetin to produce antioxidant nanoparticles with controlled size and skin tonematching colors," Molecules, vol. 24, no. 21, Article ID 3815, 2019.

[54] Z. Jurasekova, C. Domingo, J. V. García-Ramos, and S. Sánchez-Cortés, "Effect of $\mathrm{pH}$ on the chemical modification of quercetin and structurally related flavonoids characterized by optical (UV-visible and Raman) spectroscopy," Physical Chemistry Chemical Physics, vol. 16, no. 25, pp. 12802-12811, 2014.

[55] M. Balcerzak, A. Tyburska, and E. Święcicka-Füchsel, "Selective determination of $\mathrm{Fe}$ (III) in Fe (II) samples by UVspectrophotometry with the aid of quercetin and morin," Acta Pharmaceutica, vol. 58, no. 3, pp. 327-334, 2008.

[56] J. Ren, S. Meng, C. E. Lekka, and E. Kaxiras, "Complexation of flavonoids with iron: structure and optical signatures," The Journal of Physical Chemistry B, vol. 112, no. 6, pp. 1845-1850, 2008.

[57] M. J. Hynes and M. O. Coinceanainn, "The kinetics and mechanisms of the reaction of iron (III) with gallic acid, gallic acid methyl ester and catechin," Journal of Inorganic Biochemistry, vol. 85, no. 2, pp. 131-142, 2001.

[58] S. A. Cherrak, N. Mokhtari-Soulimane, F. Berroukeche et al., "In vitro antioxidant versus metal ion chelating properties of flavonoids: a structure-activity investigation," PLoS One, vol. 11, no. 10, Article ID e0165575, 2016.

[59] A. N. Pham, A. L. Rose, A. J. Feitz, and T. D. Waite, "Kinetics of $\mathrm{Fe}$ (III) precipitation in aqueous solutions at $\mathrm{pH}$ 6.0-9.5 and $25^{\circ} \mathrm{C}$," Geochimica Et Cosmochimica Acta, vol. 70, no. 3, pp. 640-650, 2006.

[60] M. K. M. Heneczkowski, D. Nowak, and A. Kuzniar, "Infrared spectrum analysis of some flavonoids," Acta Poloniae Pharmaceutica, vol. 58, no. 6, pp. 415-420, 2001.

[61] M. Catauro, F. Papale, F. Bollino et al., "Silica/quercetin sol-gel hybrids as antioxidant dental implant materials," Science and Technology of Advanced Materials, vol. 16, no. 3, Article ID 35001, 2015.

[62] J. Coates, "Interpretation of infrared spectra. A practical approch," in Encyclopedia of Analytical Chemistry, R. A. Meyers, Ed., pp. 10815-10837, John Wiley \& Sons, Chichester, UK, 2000.

[63] N. M. Mahmoodi, J. Abdi, M. Oveisi, M. Alinia Asli, and M. Vossoughi, "Metal-organic framework (MIL-100 (Fe)): synthesis, detailed photocatalytic dye degradation ability in colored textile wastewater and recycling," Materials Research Bulletin, vol. 100, pp. 357-366, 2018.

[64] J. Wahsner, E. M. Gale, A. Rodríguez-Rodríguez, and P. Caravan, "Chemistry of MRI contrast agents: current challenges and new frontiers," Chemical Reviews, vol. 119, no. 2, pp. 957-1057, 2018.

[65] P. Caravan, C. T. Farrar, L. Frullano, and R. Uppal, "Influence of molecular parameters and increasing magnetic field strength on relaxivity of gadolinium-and manganesebased T1 contrast agents," Contrast Media \& Molecular Imaging, vol. 4, no. 2, pp. 89-100, 2009.

[66] C. F. G. C. Geraldes and S. Laurent, "Classification and basic properties of contrast agents for magnetic resonance imaging," Contrast Media \& Molecular Imaging, vol. 4, no. 1, pp. 1-23, 2009.
[67] G. S. Borghetti, J. P. Carini, S. B. Honorato, A. P. Ayala, J. C. F. Moreira, and V. L. Bassani, "Physicochemical properties and thermal stability of quercetin hydrates in the solid state," Thermochimica Acta, vol. 539, pp. 109-114, 2012.

[68] I. Hajdu, M. Bodnár, G. Filipcsei et al., "Nanoparticles prepared by self-assembly of chitosan and poly- $\gamma$-glutamic acid," Colloid and Polymer Science, vol. 286, no. 3, pp. 343-350, 2008.

[69] J. D. Clogston and A. K. Patri, "Zeta potential measurement," Methods in Molecular Biology, vol. 697, pp. 63-70, 2011.

[70] S. Honary and F. Zahir, "Effect of zeta potential on the properties of nano-drug delivery systems-a review (part 2)," Tropical Journal of Pharmaceutical Research, vol. 12, no. 2, pp. 265-273, 2013.

[71] P. Cantillon-Murphy, L. L. Wald, M. Zahn, and E. Adalsteinsson, "Measuring SPIO and Gd contrast agent magnetization using 3 T MRI," NMR in Biomedicine, vol. 22, no. 8, pp. 891-897, 2009.

[72] T. Muthurajan, P. Rammanohar, N. P. Rajendran, S. Sethuraman, and U. M. Krishnan, "Evaluation of a quercetin-gadolinium complex as an efficient positive contrast enhancer for magnetic resonance imaging," RSC Advances, vol. 5, no. 106, pp. 86967-86979, 2015.

[73] A. Ashokan, V. H. Somasundaram, G. H. Gowd et al., "Biomineral nano-theranostic agent for magnetic resonance image guided, augmented radiofrequency ablation of liver tumor," Scientific Reports, vol. 7, no. 1, Article ID 14481, 2017.

[74] G. Kandasamy and D. Maity, "Recent advances in superparamagnetic iron oxide nanoparticles (SPIONs) for in vitro and in vivo cancer nanotheranostics," International Journal of Pharmaceutics, vol. 496, no. 2, pp. 191-218, 2015.

[75] Y. Bao, J. A. Sherwood, and Z. Sun, "Magnetic iron oxide nanoparticles as $\mathrm{T} 1$ contrast agents for magnetic resonance imaging," Journal of Materials Chemistry C, vol. 6, no. 6, pp. 1280-1290, 2018.

[76] J.-P. Korb and R. G. Bryant, "Magnetic field dependence of proton spin-lattice relaxation times," Magnetic Resonance in Medicine, vol. 48, no. 1, pp. 21-26, 2002.

[77] M. Rohrer, H. Bauer, J. Mintorovitch, M. Requardt, and H.-J. Weinmann, "Comparison of magnetic properties of MRI contrast media solutions at different magnetic field strengths," Investigative Radiology, vol. 40, no. 11, pp. 715-724, 2005.

[78] J. M. Hill, G. Zalos, J. P. J. Halcox et al., "Circulating endothelial progenitor cells, vascular function, and cardiovascular risk," New England Journal of Medicine, vol. 348, no. 7, pp. 593-600, 2003.

[79] S. S. Khan, M. A. Solomon, and J. P. McCoy, "Detection of circulating endothelial cells and endothelial progenitor cells by flow cytometry," Cytometry Part B: Clinical Cytometry, vol. 64 , no. 1, pp. 1-8, 2005.

[80] C. Filippone, R. Franssila, A. Kumar et al., "Erythroid progenitor cells expanded from peripheral blood without mobilization or preselection: molecular characteristics and functional competence," PLoS One, vol. 5, no. 3, Article ID e9496, 2010.

[81] M. Sanchez, F. Lodi, R. Vera et al., "Quercetin and isorhamnetin prevent endothelial dysfunction, superoxide production, and overexpression of $\mathrm{p} 47 \mathrm{phox}$ induced by angiotensin II in rat aorta," The Journal of Nutrition, vol. 137, no. 4, pp. 910-915, 2007.

[82] H. Nakayama, N. Tsuge, H. Sawada, and Y. Higashi, "Chronic intake of onion extract containing quercetin 
improved postprandial endothelial dysfunction in healthy men," Journal of the American College of Nutrition, vol. 32, no. 3, pp. 160-164, 2013.

[83] E. Y. Choi, H. Lee, J. S. Woo et al., "Effect of onion peel extract on endothelial function and endothelial progenitor cells in overweight and obese individuals," Nutrition, vol. 31, no. 9, pp. 1131-1135, 2015.

[84] J. Favre, N. Terborg, and A. J. G. Horrevoets, "The diverse identity of angiogenic monocytes," European Journal of Clinical Investigation, vol. 43, no. 1, pp. 100-107, 2013.

[85] L. Bou Khzam, O. Bouchereau, R. Boulahya et al., "Early outgrowth cells versus endothelial colony forming cells functions in platelet aggregation," Journal of Translational Medicine, vol. 13, p. 353, 2015.

[86] J. Hur, C.-H. Yoon, H.-S. Kim, J.-H. Choi et al., "Characterization of two types of endothelial progenitor cells and their different contributions to neovasculogenesis," Arteriosclerosis, Thrombosis, and Vascular Biology, vol. 24, no. 2, pp. 288-293, 2004.

[87] K. Asosingh, M. A. Aldred, A. Vasanji, J. Drazba et al., "Circulating angiogenic precursors in idiopathic pulmonary arterial hypertension," The American Journal of Pathology, vol. 172, no. 3, pp. 615-627, 2008.

[88] C.-H. Yoon, J. Hur, K.-W. Park, J.-H. Kim, C.-S. Lee et al., "Synergistic neovascularization by mixed transplantation of early endothelial progenitor cells and late outgrowth endothelial cells," Circulation, vol. 112, no. 11, pp. 1618-1627, 2005.

[89] J. Rehman, J. Li, C. M. Orschell, and K. L. March, "Peripheral blood "endothelial progenitor cells" are derived from monocyte/macrophages and secrete angiogenic growth factors," Circulation, vol. 107, no. 8, pp. 1164-1169, 2003.

[90] S. Cantoni, F. Bianchi, M. Galletti et al., "Occurring of in vitro functional vasculogenic pericytes from human circulating early endothelial precursor cell culture," Stem Cells International, vol. 2015, Article ID 943671, 11 pages, 2015.

[91] A. Blocki, Y. Wang, M. Koch et al., "Sourcing of an alternative pericyte-like cell type from peripheral blood in clinically relevant numbers for therapeutic angiogenic applications," Molecular Therapy, vol. 23, no. 3, pp. 510-522, 2015.

[92] I. Kanzler, N. Tuchscheerer, G. Steffens et al., "Differential roles of angiogenic chemokines in endothelial progenitor cell-induced angiogenesis," Basic Research in Cardiology, vol. 108, no. 1, Article ID 310, 2013.

[93] J. M. Melero-Martin, M. E. De Obaldia, S.-Y. Kang et al., "Engineering robust and functional vascular networks in vivo with human adult and cord blood-derived progenitor cells," Circulation Research, vol. 103, no. 2, pp. 194-202, 2008.

[94] M. B. Britten, N. D. Abolmaali, B. Assmus et al., "Infarct remodeling after intracoronary progenitor cell treatment in patients with acute myocardial infarction (topcare-ami)," Circulation, vol. 108, no. 18, pp. 2212-2218, 2003.

[95] V. Schächinger, B. Assmus, M. B. Britten et al., "Transplantation of progenitor cells and regeneration enhancement in acute myocardial infarction," Journal of the American College of Cardiology, vol. 44, no. 8, pp. 1690-1699, 2004.

[96] D. Sukmawati and R. Tanaka, "Introduction to next generation of endothelial progenitor cell therapy: a promise in vascular medicine," American Journal of Translational Research, vol. 7, no. 3, pp. 411-421, 2015.

[97] M. G. Roubelakis, G. Tsaknakis, K. I. Pappa, N. P. Anagnou, and S. M. Watt, "Spindle shaped human mesenchymal stem/ stromal cells from amniotic fluid promote neovascularization," PLoS One, vol. 8, no. 1, Article ID e54747, 2013.

[98] W. J. Du, Y. Chi, Z. X. Yang et al., "Heterogeneity of proangiogenic features in mesenchymal stem cells derived from bone marrow, adipose tissue, umbilical cord, and placenta," Stem Cell Research \& Therapy, vol. 7, no. 163, pp. 1-11, 2016.

[99] E. J. Ngen, L. Wang, Y. Kato et al., "Imaging transplanted stem cells in real time using an MRI dual-contrast method," Scientific Reports, vol. 5, no. 1, Article ID 13628, 2015.

[100] J.-H. Sun, Y.-L. Zhang, C.-H. Nie et al., "In vitro labeling of endothelial progenitor cells isolated from peripheral blood with superparamagnetic iron oxide nanoparticles," Molecular Medicine Reports, vol. 6, no. 2, pp. 282-286, 2012.

[101] S.-K. Kim, D.-K. Lee, H.-J. Lim, and U. Sim, "In vitro targeting and imaging of neurogenic differentiation in mouse bone-marrow derived mesenchymal stem cells with superparamagnetic iron oxide nanoparticles," Applied Sciences, vol. 9, no. 16, p. 3259, 2019.

[102] E. Küstermann, U. Himmelreich, K. Kandal et al., "Efficient stem cell labeling for MRI studies," Contrast Media \& Molecular Imaging, vol. 3, no. 1, pp. 27-37, 2008.

[103] H. E. Daldrup-Link, M. Rudelius, R. A. J. Oostendorp et al., "Targeting of hematopoietic progenitor cells with MR contrast agents," Radiology, vol. 228, no. 3, pp. 760-767, 2003.

[104] I. E. Haedicke, S. Loai, and H. L. M. Cheng, “An efficient T1 contrast agent for labeling and tracking human embryonic stem cells on MRI," Contrast Media \& Molecular Imaging, vol. 2019, Article ID 3475786, 11 pages, 2019.

[105] A. Crabbe, C. Vandeputte, T. Dresselaers et al., "Effects of MRI contrast agents on the stem cell phenotype," Cell Transplantation, vol. 19, no. 8, pp. 919-936, 2010.

[106] I. E. Haedicke, T. Li, Y. L. K. Zhu et al., "An enzymeactivatable and cell-permeable MnIII-porphyrin as a highly efficient T1 MRI contrast agent for cell labeling," Chemical Science, vol. 7, no. 7, pp. 4308-4317, 2016.

[107] A. A. A. Ali, R. A. Shahror, and K.-Y. Chen, "Efficient labeling of mesenchymal stem cells for high sensitivity longterm MRI monitoring in live mice brains," International Journal of Nanomedicine, vol. 15, pp. 97-114, 2020.

[108] H. Wang, V. C. Jordan, I. A. Ramsay et al., "Molecular magnetic resonance imaging using a redox-active iron complex," Journal of the American Chemical Society, vol. 141, no. 14, pp. 5916-5925, 2019.

[109] B. S. Weerakoon, T. Osuga, and T. Konishi, "Assessment the optimal effect of time of repetition: extrinsic pulse parameter on Gd-dtpa enhanced, spin-echo T1-weighted MR images under low magnetic field strength," International Journal of Medical Physics, Clinical Engineering and Radiation Oncology, vol. 5, pp. 196-203, 2016.

[110] K. Geng, Z. X. Yang, D. Huang et al., "Tracking of mesenchymal stem cells labeled with gadolinium diethylenetriamine pentaacetic acid by $7 \mathrm{~T}$ magnetic resonance imaging in a model of cerebral ischemia," Molecular Medicine Reports, vol. 11, no. 2, pp. 954-960, 2015.

[111] S. Loai, I. Haedicke, Z. Mirzaei et al., "Positive-contrast cellular MRI of embryonic stem cells for tissue regeneration using a highly efficient T1 MRI contrast agent," Journal of Magnetic Resonance Imaging, vol. 44, no. 6, pp. 1456-1463, 2016.

[112] A. Venter, D. A. Szulc, S. Loai et al., "A manganese porphyrin-based T1 contrast agent for cellular MR imaging of 
human embryonic stem cells," Scientific Reports, vol. 8, no. 1, Article ID 12129, 2018.

[113] S. G. Crich, L. Biancone, V. Cantaluppi et al., "Improved route for the visualization of stem cells labeled with a Gd-/ Eu-chelate as dual (MRI and fluorescence) agent," Magnetic Resonance in Medicine, vol. 51, no. 5, pp. 938-944, 2004. 